OPEN ACCESS

Edited by: Hongyue Dang,

Xiamen University, China

Reviewed by:

Wei Xie,

Tongji University, China

Jake Bailey,

University of Minnesota, United States

*Correspondence: Yu Zhen

zhenyu@ouc.edu.cn

Specialty section: This article was submitted to

Aquatic Microbiology,

a section of the journal

Frontiers in Microbiology

Received: 07 May 2017 Accepted: 18 October 2017 Published: 07 November 2017

Citation:

Zhang $Y$, Wang $X$, Zhen $Y, M i T$, $\mathrm{He} H$ and Yu Z (2017) Microbial Diversity and Community Structure of Sulfate-Reducing and Sulfur-Oxidizing Bacteria in Sediment Cores from the East China Sea. Front. Microbiol. 8:2133. doi: 10.3389/fmicb.2017.02133

\section{Microbial Diversity and Community Structure of Sulfate-Reducing and Sulfur-Oxidizing Bacteria in Sediment Cores from the East China Sea}

\author{
Yu Zhang ${ }^{1,2,3}$, Xungong Wang ${ }^{1,2,3}$, Yu Zhen ${ }^{1,2,3 *}$, Tiezhu Mi ${ }^{1,2,3}$, Hui He ${ }^{2,3,4}$ and Zhigang $\mathrm{Yu}^{3,5}$ \\ ${ }^{1}$ College of Environmental Science and Engineering, Ocean University of China, Qingdao, China, ${ }^{2}$ Key Laboratory of Marine \\ Environment and Ecology, Ministry of Education, Qingdao, China, ${ }^{3}$ Laboratory for Marine Ecology and Environmental \\ Science, Qingdao National Laboratory for Marine Science and Technology, Qingdao, China, ${ }^{4}$ College of Marine Life Science, \\ Ocean University of China, Qingdao, China, ${ }^{5}$ Key Laboratory of Marine Chemical Theory and Technology, Ministry of \\ Education, Qingdao, China
}

Sulfate-reducing bacteria (SRB) and sulfur-oxidizing bacteria (SOB) have been studied extensively in marine sediments because of their vital roles in both sulfur and carbon cycles, but the available information regarding the highly diverse SRB and SOB communities is not comprehensive. High-throughput sequencing of functional gene amplicons provides tremendous insight into the structure and functional potential of complex microbial communities. Here, we explored the community structure, diversity, and abundance of SRB and SOB simultaneously through 16S rRNA, dsrB and soxB gene high-throughput sequencing and quantitative PCR analyses of core samples from the East China Sea. Overall, high-throughput sequencing of the $d s r B$ and soxB genes achieved almost complete coverage (>99\%) and revealed the high diversity, richness, and operational taxonomic unit (OTU) numbers of the SRB and SOB communities, which suggest the existence of an active sulfur cycle in the study area. Further analysis demonstrated that rare species make vital contributions to the high richness, diversity, and OTU numbers obtained. Depth-based distributions of the $d s r B$, soxB, and $16 \mathrm{~S}$ rRNA gene abundances indicated that the SRB abundance might be more sensitive to the sedimentary dynamic environment than those of total bacteria and SOB. In addition, the results of unweighted pair group method with arithmetic mean (UPGMA) clustering analysis and redundancy analysis revealed that environmental parameters, such as depth and dissolved inorganic nitrogen concentrations, and the sedimentary dynamic environment, which differed between the two sampling stations, can significantly influence the community structures of total bacteria, SRB, and SOB. This study provided further comprehensive information regarding the characteristics of SRB and SOB communities.

Keywords: sulfate-reducing bacteria, sulfur-oxidizing bacteria, microbial community, high-throughput sequencing, East China Sea 


\section{INTRODUCTION}

Sulfur cycling, one of the key biological processes in marine sediments, is dominated by sulfate-reducing bacteria (SRB) and sulfur-oxidizing bacteria (SOB). Dissimilatory sulfate reduction, which is mediated by SRB, is considered the main process in the biomineralization of organic matter in marine sediments and might account for up to $50 \%$ of organic matter mineralization in most continental shelf sediments (Jørgensen, 1982). In addition, as much as $12-29 \%$ of the organic carbon flux on the ocean seafloor is channeled through sulfate reduction (Bowles et al., 2014). Interestingly, $80-95 \%$ of the massive amount of hydrogen sulfide formed through sulfate reduction is recycled within sediments and gradually oxidized back to sulfate (Jørgensen and Nelson, 2004). Thus, SRB and SOB control the key processes of organic matter degradation and the biogeochemical cycling of sulfur and carbon. Studying the community structure and diversity of SRB and SOB is important for revealing the roles of these bacteria in the biogeochemical cycles of carbon and sulfur and for providing insight into the biological factors driving the marine sulfur cycle.

SRB and SOB show high diversity, including both phylogenetic and metabolic diversity (Ghosh and Dam, 2009; Müller et al., 2014). To explore the environmental abundance and diversity of SRB and SOB, genes encoding key enzymes in the sulfate reduction and sulfur oxidation biochemical pathways have been used as molecular markers. For example, the dissimilatory sulfite reductase gene $d s r A B$, which encodes a key enzyme that catalyzes the last, essential step in the dissimilatory sulfate reduction pathway, has been frequently employed as a functional gene in studies of SRB in various environments (Foti et al., 2007; Pester et al., 2012; He et al., 2015). The known SOB have been demonstrated to use different enzymes, pathways, and electron transport and energy conservation mechanisms for the oxidation of sulfide. The sulfur-oxidizing (Sox) (Meyer et al., 2007), reverse dissimilatory sulfite reductase (Loy et al., 2009), adenosine-5-phosphosulfate reductase (Meyer and Kuever, 2007), and sulfide quinone oxidoreductase enzyme systems (Pham et al., 2008) play vital roles in sulfide oxidation, and among these, the Sox multi-enzyme system is considered a fundamental and primordial molecular mechanism for sulfur oxidation (Ghosh and Dam, 2009) that is widespread among the known SOB (Meyer et al., 2007). Moreover, the soxB gene, which encodes the SoxB subunit of the Sox enzyme system, has been widely employed to characterize the abundance and diversity of SOB in various environments (Kojima et al., 2014; Thomas et al., 2014; Tourna et al., 2014).

The diversity and community structure of SRB and SOB have, to date, been studied using denaturing gradient gel electrophoresis (DGGE) (Varon-Lopez et al., 2013; Yang et al., 2015), restriction fragment length polymorphism (Luo et al., 2011; Reed and Martiny, 2013), and clone library approaches (Yang et al., 2013; Purcell et al., 2014). However, obtaining comprehensive information about the highly diverse SRB and SOB communities, particularly SRB and SOB from the prime habitats of marine sediments, using these methods is challenging (Aoki et al., 2015; Zhang et al., 2016). High-throughput sequencing, which constitutes a powerful approach for achieving complete coverage of microbial communities, has been recently applied in the analysis of microbial community diversity and composition. For instance, high-throughput sequencing of the $16 \mathrm{~S}$ rRNA gene revealed the presence of a number of novel bacterial groups (Zhu et al., 2013; Mahmoudi et al., 2015) and a high diversity of bacteria (Wang et al., 2015). Moreover, the community structure and diversity of functional microbes, particularly nitrogen-cycling microbes, such as ammoniaoxidizing bacteria, ammonia-oxidizing archaea and denitrifying microbes, have been investigated through high-throughput sequencing analyses of functional genes (Tago et al., 2014; Saarenheimo et al., 2015). However, only a few studies have evaluated the community structure and diversity of SRB and SOB using high-throughput sequencing (Meyer et al., 2016; Cui et al., 2017).

The East China Sea (ECS) is the largest marginal sea of the Northwest Pacific Ocean, with a vast continental area of $0.5 \times 10^{12} \mathrm{~m}^{2}$. The Changjiang River (Yangtze River), which transports great quantities of freshwater, nutrients, organic matter, and other chemical elements into the ECS, has a marked effect on the sea (Milliman and Meade, 1983; Beardsley et al., 1985). The ECS is also influenced by the warm and oligotrophic Taiwan Warm Currents in the south and the Kuroshio Current (from the Western Equatorial Pacific) in the east (Jiao et al., 2005). More interestingly, the ECS has also experienced serious environmental problems, including eutrophication, harmful algal blooms, and chemical pollution (Shen et al., 2011; Cheng et al., 2012; Yu et al., 2013). Because of the strong influence of its riverine inputs, currents and environmental problems, the ECS exhibits complex physical and chemical conditions and has become an ideal study area for ecological investigations of the temporal and spatial dynamics of biota (Dang et al., 2008; Xiong et al., 2014; Zhang et al., 2014). Increasing research efforts have focused on microbial ecology in the ECS, particularly the microbial community structure and diversity of organisms associated with the sulfur cycle, such as SRB and SOB (Nie et al., 2009; Wu et al., 2009; He et al., 2015); however, because of the limitations of the applied methods (DGGE or clone libraries), only a few dominant species have been identified. In the present study, the 16S rRNA gene and two functional genes ( $d s r B$ and $\operatorname{sox} B$ ) were combined in a high-throughput sequencing analysis, and this combination allowed for an in-depth analysis of the community structure and diversity of SRB and SOB in sediment cores from the ECS. In addition, quantitative PCR (qPCR) was performed to reveal the vertical distribution of SRB and SOB populations and provide insight into the SRB and SOB community characteristics.

\section{MATERIALS AND METHODS}

\section{Site and Sampling Description}

Two core samples from ECS sediments were collected from station S31 (length: $21 \mathrm{~cm}$ ) and station S33 (length: $50 \mathrm{~cm}$ ) during a research cruise in July 2011 on the R/V Run-Jiang (Supplementary Figure S1). A QuAAtro nutrient auto analyzer 
(Seal Analytical Ltd., United Kingdom) was used to measure the pore-water dissolved $\mathrm{N}, \mathrm{P}$, and $\mathrm{Si}$ concentrations of the following: nitrate $\left(\mathrm{NO}_{3}-\mathrm{N}\right)$, nitrite $\left(\mathrm{NO}_{2}-\mathrm{N}\right)$, ammonium $\left(\mathrm{NH}_{4}\right.$ $\mathrm{N})$, phosphate $\left(\mathrm{PO}_{4}-\mathrm{P}\right)$, and silicate $\left(\mathrm{SiO}_{3}-\mathrm{Si}\right)$ (Supplementary Table S1). The sampling methods as well as the methods used for the determination of environmental parameters $[\mathrm{pH}$ and the concentrations of $\mathrm{Fe}(\mathrm{II}), \mathrm{Mn}(\mathrm{II})$, sulfate and excess ${ }^{210} \mathrm{~Pb}$ ] were described in detail by He et al. (2015) (Supplementary Table S1 and Figure S2). After collection, the samples from stations S31 and S33 were divided into three depth sections $(0-4,8-12$, and $16-20 \mathrm{~cm})$ and five depth sections $(0-4,8-12,16-20,32-36$, and $46-50 \mathrm{~cm})$, respectively, and subsequently frozen at $-80^{\circ} \mathrm{C}$ for nucleic acid extraction.

\section{DNA Extraction}

Genomic DNA was extracted from each sediment sample using the PowerSoil DNA Isolation Kit (Mo Bio Laboratories Inc., Carlsbad, CA, United States) according to the manufacturer's recommended protocol. The extracted DNA was stored at $-80^{\circ} \mathrm{C}$ prior to further analyses.

\section{High-Throughput Sequencing and Data Processing}

\section{Illumina HiSeq2500 (PE250) Sequencing and Analysis}

The community structure, richness, and diversity of total bacteria and SRB were studied through Illumina HiSeq2500 (PE250) sequencing based on the $16 \mathrm{~S}$ rRNA and $d s r B$ genes. Fragments of the $16 \mathrm{~S}$ rRNA gene ( $\sim 466 \mathrm{bp}, \mathrm{V} 3-\mathrm{V} 4$ region) and $d s r B$ gene $(\sim 350 \mathrm{bp})$ were amplified using the primer pairs $341 \mathrm{~F} / 806 \mathrm{R}$ and DSRp2060F/DSR4R, respectively (Supplementary Table S2); these primer pairs have been widely employed in previous studies of bacteria from various environments (Geets et al., 2006; Michelsen et al., 2014). PCR amplification was performed in a 30$\mu \mathrm{L}$ reaction volume containing $15 \mu \mathrm{L}$ of Phusion ${ }^{\circledR}$ High-Fidelity PCR Master Mix (New England Biolabs), $0.2 \mu \mathrm{M}$ forward and reverse primers, and approximately $10 \mathrm{ng}$ of template DNA. The amplification reactions were performed in a thermal cycler (BioRad T100, United States) and consisted of an initial denaturation step at $98^{\circ} \mathrm{C}$ for $1 \mathrm{~min}$ followed by 30 cycles of denaturation at $98^{\circ} \mathrm{C}$ for $10 \mathrm{~s}$, annealing at $50^{\circ} \mathrm{C}$ for $30 \mathrm{~s}$, elongation at $72^{\circ} \mathrm{C}$ for $30 \mathrm{~s}$, and a final step at $72^{\circ} \mathrm{C}$ for $5 \mathrm{~min}$. The PCR products were analyzed via $2 \%$ agarose gel electrophoresis to assess the quality and size of the resultant amplicons. The PCR products were then mixed at equidensity ratios and purified using the GeneJET Gel Extraction Kit (Thermo Fisher Scientific). 16S rRNA and $d s r B$ gene libraries were subsequently prepared using the NEB Next ${ }^{\circledR}$ Ultra $^{\mathrm{TM}}$ DNA Library Prep Kit (New England Biolabs), and the libraries were sequenced on the Illumina HiSeq2500 (PE250) platform following the manufacturer's recommendations.

Paired-end reads (16S rRNA and $d s r B$ ) were assigned to the samples based on their unique barcode, truncated by removing the barcode and primer sequence, and then merged using FLASH (Version 1.2.7) (Magoè and Salzberg, 2011). The merged reads were subsequently subjected to quality-based filtering with QIIME (Caporaso et al., 2010). Briefly, the reads were truncated at any site containing more than three sequential bases with a Phred quality score (Q) below 20 and any read containing ambiguous base calls and reads with less than $75 \%$ (with respect to the total read length) consecutive high-quality base calls (Wang et al., 2016) were discarded.

\section{Pyrosequencing and Sequence Analysis}

The soxB gene $(\sim 750$ bp $)$ was amplified with the soxB693F/soxB1446B primer set, which was previously shown to yield the most successful and reliable amplification results (Supplementary Table S2) (Meyer et al., 2007). The 25- $\mu \mathrm{L}$ amplification reaction for the $\operatorname{sox} B$ gene included $4 \mu \mathrm{L}$ of $5 \times$ Q5 reaction buffer (New England Biolabs), $2 \mu \mathrm{L}$ of $2.5 \mathrm{mM}$ deoxynucleoside triphosphate $(\mathrm{dNTP}) \operatorname{mix}, 5 \mu \mathrm{L}$ of $5 \times \mathrm{Q} 5$ High GC Enhancer, $1 \mu \mathrm{L}$ of each primer $(10 \mu \mathrm{M}), 0.25 \mu \mathrm{L}$ of Q5 High-Fidelity DNA Polymerase (New England Biolabs), $2.5 \mu \mathrm{L}$ of template DNA, and $8.25 \mu \mathrm{L}$ of double-distilled $\mathrm{H}_{2} \mathrm{O}$. The reactions were maintained at $98^{\circ} \mathrm{C}$ for $5 \mathrm{~min}$ for DNA denaturation; they were then subjected to 32 cycles of $98^{\circ} \mathrm{C}$ for $30 \mathrm{~s}, 55^{\circ} \mathrm{C}$ for $40 \mathrm{~s}$, and $72^{\circ} \mathrm{C}$ for $1 \mathrm{~min}$ and then to a final extension at $72^{\circ} \mathrm{C}$ for $7 \mathrm{~min}$ to ensure complete amplification. The obtained PCR product was cut from a 1.5\% agarose gel and purified using the AxyPrep DNA Gel Extraction Kit (Axygen, AP-GX-250). Pyrosequencing of the soxB gene was subsequently conducted using the 454 FLX+ platform according to the manufacturer's recommended protocol.

The raw data were processed using the QIIME pipeline (Caporaso et al., 2010). For quality filtering, low-quality reads shorter than $150 \mathrm{bp}$, reads with an average quality score below 19, sequences with ambiguous base calls and sequences with homopolymer runs exceeding 6 bp were removed (ElChakhtoura et al., 2015). Moreover, the barcode and primer regions were trimmed from the sequences.

\section{Operational Taxonomic Unit Clusters and Taxonomic Assignment}

After quality control, UPARSE (Edgar, 2013) was employed to cluster all of the clean reads into operational taxonomic units (OTUs) using 97 and 90\% similarity cutoffs (Petri et al., 2001; Müller et al., 2014) for the 16S rRNA gene and functional genes $(d s r B$ and $\operatorname{sox} B)$, respectively. In addition, the most abundant sequence from each OTU was selected as the representative sequence. Taxonomic information for each representative $16 \mathrm{~S}$ rRNA and functional gene sequence was obtained by searching the Greengenes and the NCBI (National Center for Biotechnology Information) databases, respectively. Reads that did not match any sequences in the database were clustered into the unclassified group.

\section{Quantification of Gene Copies in Sediments}

The total bacterial 16S rRNA gene, the SRB $d s r B$ gene, and the $\mathrm{SOB}$ soxB gene in the sediment samples were amplified using the primers 341F/518R, DSRp2060F/DSR4R, and soxB693F/soxB1164BK145, respectively (Supplementary Table S2); these primers were demonstrated to work effectively in previous studies (Geets et al., 2006; Dang et al., 2010; 
Krishnani et al., 2010). The method used for quantification of the $d s r B$ and 16S rRNA genes in the investigated samples has been described previously (He et al., 2015). All qPCR assays targeting the $s o x B$ gene were performed in triplicate using an $\mathrm{ABI}$ PRISM $^{\circledR} 7500$ Sequence Detection System (Applied Biosystems, Foster City, CA, United States). Each 20- $\mathrm{L}$ q qCR mixture contained the following reagents: $10 \mu \mathrm{L}$ of FastStart Universal SYBR Green Master Mix (Rox) (Roche Diagnostics, Mannheim, Germany), $0.2 \mu \mathrm{g} \mu \mathrm{L}^{-1}$ of bovine serum albumin, $0.4 \mu \mathrm{M}$ of each primer, and $2.0 \mu \mathrm{L}$ of template DNA. The qPCR amplification conditions were as follows: $95^{\circ} \mathrm{C}$ for $10 \mathrm{~min}$ followed by 40 cycles of $15 \mathrm{~s}$ at $95^{\circ} \mathrm{C}, 45 \mathrm{~s}$ at $55^{\circ} \mathrm{C}$, and $1 \mathrm{~min}$ at $72^{\circ} \mathrm{C}$. To evaluate the specificity of the $\mathrm{qPCR}$ amplification, the PCR products were sequenced by the Beijing Genomics Institute. In addition, the specificity of the amplification products was verified by melting curve analysis and visualized in agarose gels. Melting curves were obtained at $60-95^{\circ} \mathrm{C}$; a read was obtained after every $1^{\circ} \mathrm{C}$ increase in temperature, and the temperature was maintained for $1 \mathrm{~s}$ between reads. The resultant qPCR data were analyzed using ABI PRISM 7500 SDS software.

Plasmids containing the target gene fragments were extracted from Escherichia coli hosts using a FastPlasmid Mini Kit (CWBIO, Beijing, China) and quantified using a Picodrop microliter spectrophotometer (Picodrop, Saffron Walden, Essex, United Kingdom). Standard curves for the qPCR assays were obtained with serial 10 -fold dilutions of reference plasmids. Standard curves with efficiencies ranging from 90 to $110 \%$ and a corresponding $R$-value greater than 0.99 were considered credible.

\section{Statistical Analyses}

After randomly reducing the number of reads to the lowest number of reads in any individual sample, the richness indices (Chao 1 estimates), diversity indices (Shannon index), and Good's coverage were obtained with QIIME (Caporaso et al., 2010). Furthermore, unweighted pair group method with arithmetic mean (UPGMA) clustering based on a weighted UniFrac distance matrix was conducted using QIIME to examine the differences in the bacterial communities between the sediment samples. The relationships between community composition and sediment characteristics were examined using BIOENV, detrended correspondence analysis (DCA), and redundancy analysis (RDA) with the R package vegan (Oksanen et al., 2011). The DCA analysis indicated that a linearmodel-based RDA analysis was more suitable than unimodal CCA for our data (Hernández-Landa et al., 2015). BIOENV provides the subset of environmental variables that best explain the community variation among the sampling stations using Spearman rank correlation, and RDA determines the percentage of the community composition variation explained by this subset of environmental variables. The significance of the environmental variables was tested by a Monte Carlo permutation test (999 unrestricted permutations, $p<0.05$ ). A Pearson's correlation analysis between microbial abundance and environmental parameters was performed using SPSS statistics software.

\section{Nucleotide Sequence Accession Numbers}

The sequence data generated in this study were deposited in the NCBI Short Read Archive database under accession numbers SRP077048 (16S rRNA), SRP077077 (dsrB), and SRP077086 (soxB).

\section{RESULTS}

\section{Bacterial 16S rRNA Gene Analysis}

A total of 371,534 high-quality $16 \mathrm{~S}$ rRNA gene sequences with an average length of $418 \mathrm{bp}$ were obtained from an Illumina HiSeq2500 (PE250) sequencing analysis of the eight sediment samples. The high-quality sequences were clustered into OTUs with $97 \%$ sequence similarity. Accordingly, bacterial richness (Chao 1 estimator) and diversity (Shannon index) estimates were calculated for each sample and are shown in Table 1. Good's coverage estimate for each sample ranged from 98.2 to $99.2 \%$, indicating that the sampling was sufficient to cover almost all bacterial communities. A total of 1,607-2,196 OTUs with $97 \%$ similarity were identified in the eight sediment samples. The samples from S33 exhibited more OTUs than those from S31, and the surface sediment $(0-4 \mathrm{~cm})$ samples presented the lowest number of OTUs at each station. The diversity indices (Shannon indices) and species richness indices (Chao 1) indicated that the samples from S33 displayed greater richness and diversity than those from S31. These results revealed higher microbial diversity at S33. Furthermore, the diversity indices did not change markedly with increasing depth. In addition, the lowest and the highest richness indices were obtained for the $0-4$ and $32-36 \mathrm{~cm}$ sections, respectively.

In total, 52 different bacterial phyla were detected across all sediment samples, and the dominant phyla (exhibiting a relative abundance $>1 \%$ in at least one sample), which accounted for more than $94.57 \%$ of the total sequences in each sample, are shown in Figure 1. Proteobacteria was the most abundant phylum in all samples and accounted for $36.9-62.4 \%$ of all sequences. After the relative abundance of Proteobacteria reached its peak value at a depth of $8-12 \mathrm{~cm}$, it exhibited a tendency to significantly decline with increasing depth at each station. Within Proteobacteria, the majority of sequences were assigned to Deltaproteobacteria (25.8-70.0\%), Gammaproteobacteria (12.746.5\%), and Alphaproteobacteria (11.1-34.3\%) (Figure 2). Furthermore, Deltaproteobacteria and Alphaproteobacteria were more abundant at $\mathrm{S} 33$, whereas Gammaproteobacteria was more abundant at S31.

In the shallow sediment layers $(0-20 \mathrm{~cm})$ from each station, Actinobacteria and Acidobacteria were the second and third most dominant communities, accounting for 5.8-27.6 and 6.5$9.4 \%$ of all bacteria amplicons, respectively. Furthermore, the relative abundance of Actinobacteria decreased with increasing depth at each station, whereas the relative abundance of Acidobacteria increased with increasing depth at S31 and decreased with increasing depth at S33. In the deeper sediment layers (32-36 and 46-50 cm) from S33, Chloroflexi and 
TABLE 1 | Vertical distribution of sediment bacterial community diversity and richness estimators based on the 16S rRNA gene.

\begin{tabular}{|c|c|c|c|c|c|c|}
\hline Station & Depth (cm) & Read number & OTUs & Shannon & Chao 1 & Good's coverage (\%) \\
\hline & $8-12$ & 50,347 & 1,733 & 7.883 & 1975.441 & 98.5 \\
\hline \multirow[t]{4}{*}{ S33 } & $0-4$ & 40,919 & 1,766 & 8.496 & 1818.074 & 99.2 \\
\hline & $8-12$ & 46,306 & 1,989 & 8.536 & 2237.209 & 98.6 \\
\hline & $16-20$ & 49,152 & 2,123 & 8.573 & 2325.423 & 98.5 \\
\hline & $46-50$ & 51,084 & 1,975 & 8.589 & 2297.087 & 98.6 \\
\hline
\end{tabular}

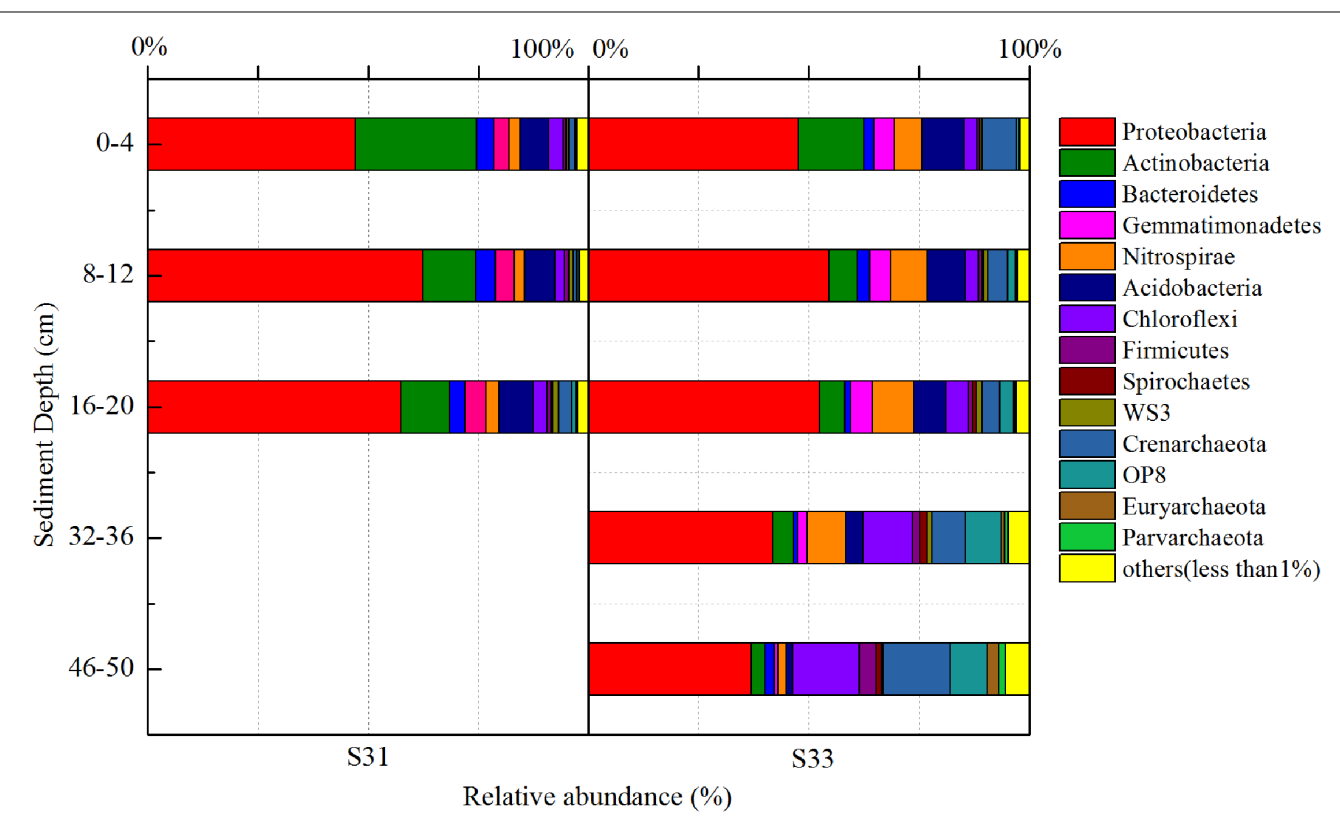

FIGURE 1 | 16S rRNA gene-based relative abundance of dominant bacterial groups (relative abundance >1\%) observed in core samples collected from the East China Sea.

Crenarchaeota were the second and third most dominant communities, accounting for 13.1 and $11.4 \%$ of bacterial amplicons, respectively.

Above all, the bacterial communities at the two investigated stations showed similarities in their dominant groups of phyla, particularly in shallow sediment layers. However, certain variations, such as differences in class groups, were observed between the two stations. The similarities and dissimilarities between the bacterial communities in the different sediment samples were further quantified through UPGMA clustering analysis based on the weighted UniFrac distance metric (Figure 3A). Overall, the bacterial community structures in the shallow sediment layers $(0-20 \mathrm{~cm})$ from S31 and S33 were similar, and those in the deeper sediment layers (32-36 and $46-50 \mathrm{~cm}$ ) from S33 clustered separately. These findings, which showed high jackknife support, suggest that sampling depth plays a relatively important role in bacterial community structure. However, analysis of the cluster containing the shallow sediment samples revealed that the samples from S31 formed a separate group and clustered away from the samples from S33, revealing the existence of differences in bacterial community structure between the two sampling sites.

\section{Functional Gene Analysis Functional Gene Diversity}

The total numbers of high-quality sequences from the $d s r B$ and soxB genes obtained from all samples were 615,062 and 107,688 , respectively. Using a similarity cutoff of $90 \%$, these sequences were classified into 829 OTUs for the $d s r B$ gene and 380 OTUs for the soxB gene. The corresponding species richness (Chao 1 estimator) and diversity estimates (Shannon index) were calculated for each sample and are listed in Tables 2A,B. Good's coverage values of the functional genes were all above $99 \%$, indicating that the obtained sequences could adequately reflect the diversity of SRB and SOB in the sediments. Overall, the soxB gene diversity was substantially higher than that of the $d s r B$ gene, whereas the $d s r B$ gene richness was markedly higher than that of the $\operatorname{sox} B$ gene.

The diversity indices of the $d s r B$ gene did not change markedly with increasing depth at S31 and increased with increasing depth 


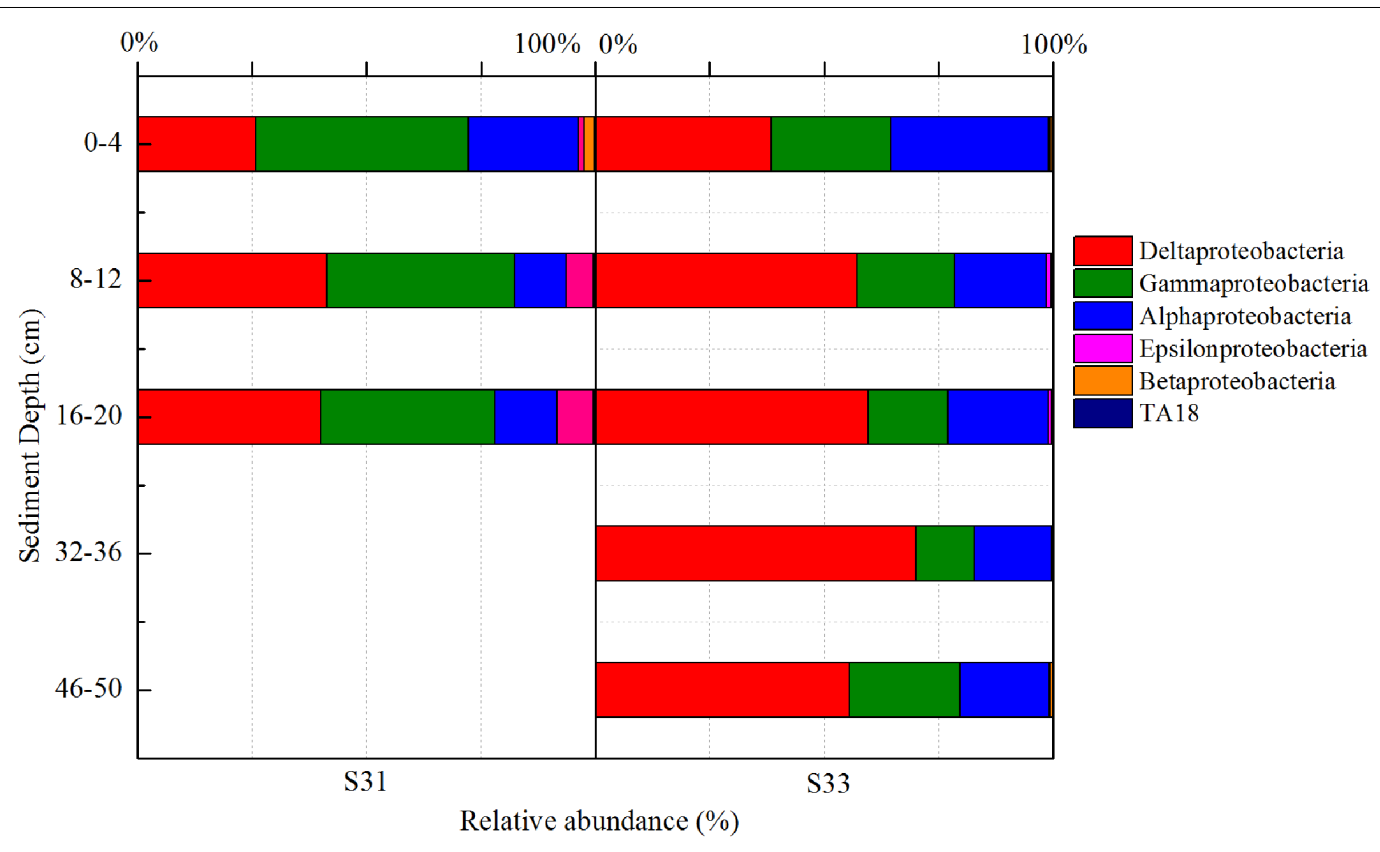

FIGURE 2 | 16S rRNA gene-based relative abundance of different classes of Proteobacteria in core samples collected from the East China Sea.

at S33. Moreover, the diversity indices of the $d s r B$ gene in the shallow sediment layers $(0-20 \mathrm{~cm})$ from S31 were greater than those from S33 and lower than those obtained for the deeper sediment layers $(32-36$ and $40-46 \mathrm{~cm}$ ) from S33. The richness of the $d s r B$ gene was lowest in the $8-12 \mathrm{~cm}$ sediment depth range at station S31 and reached its peak value in the depth range of 32$36 \mathrm{~cm}$ at station S33. For the soxB gene, the diversity and richness indices decreased with increasing depth at S31, whereas at S33, the diversity and richness indices decreased with increasing depth until suddenly increasing and peaking in the depth range of $46-50 \mathrm{~cm}$.

\section{Functional Gene Community Composition \\ dsrB gene}

The community structure of the $d s r B$ gene in the samples was analyzed based on the 109 dominant (showing $>1 \%$ abundance in at least one sample) and core (common to all samples) OTUs (representing 85.3-98.2\% of the total sequences). Overall, 103 OTUs, accounting for $81.1-94.7 \%$ of the total $d s r B$ sequences, were affiliated with Deltaproteobacteria, and six OTUs, representing $0.45-6.6 \%$ of the total $d s r B$ sequences, were classified as belonging to Firmicutes. As shown in Figure 4, among the dominant Deltaproteobacteria, the majority of sequences (15 OTUs with relative abundances ranging from 40.91 to $73.36 \%$ ) could not be assigned at the class or family levels. The 42 OTUs belonging to the Desulfobacteraceae family (ranging from 9.60 to $34.05 \%$ ) represented a significant fraction and tended to increase with increasing depth at each station. A total of 42 OTUs with relative abundances ranging from 4.23 to 7.49\% were affiliated with Syntrophaceae. The Desulfobulbaceae family (four OTUs) reached an abundance of $4.06 \%$ on average at S31 but only accounted for $0.40 \%$ of the sequences at S33.
The relative abundance of all dominant OTUs (total of 28 OTUs) from each sample exceeded $80 \%$, indicating that the community composition of the $d s r B$ gene in sediments was well reflected by the dominant OTUs. Thus, the distribution of dominant OTUs was analyzed to better understand the composition and structure of the $d s r B$ gene in the samples (Figure 5). OTU1, showing relative abundances ranging from 38.8 to $63.8 \%$, was the predominant SRB group in all sediment layers. Moreover, the relative abundance of OTU1 decreased with increasing depth at S33, whereas at S31, no significant difference was observed between the depth ranges of $0-4,16-$ 20 , and $8-12 \mathrm{~cm}$. In addition, the relative abundance of OTU1 in the shallow sediment layers $(0-20 \mathrm{~cm})$ from S33 was greater than that in the samples from S31. OTU2 reached an average abundance of $3.98 \%$ at S31 but only accounted for $0.07-0.5 \%$ of the sequences at S33. A similar trend of differences was observed for OTU5, OTU6, OTU7, OTU8, and OTU9, whereas OTU3, OTU4, OTU10, OTU11, and OTU12 were more abundant at S33 than at $\mathrm{S} 31$.

Taken together, the results regarding the distribution of dominant OTUs at S31 and S33 indicated certain differences. Interestingly, similar results were obtained via UPGMA clustering analysis (Figure 3B). The UPGMA analysis showed that the SRB communities at S31 and S33 clustered separately from each other, revealing the dissimilarity in the SRB community structure between the two sampling stations and among different sediment depths.

\section{soxB gene}

Taxonomic classification revealed that Proteobacteria accounted for the most abundant clades at the phylum level, representing $46.91-77.17 \%$ (131 OTUs) of the sequences. Chlorobi and 

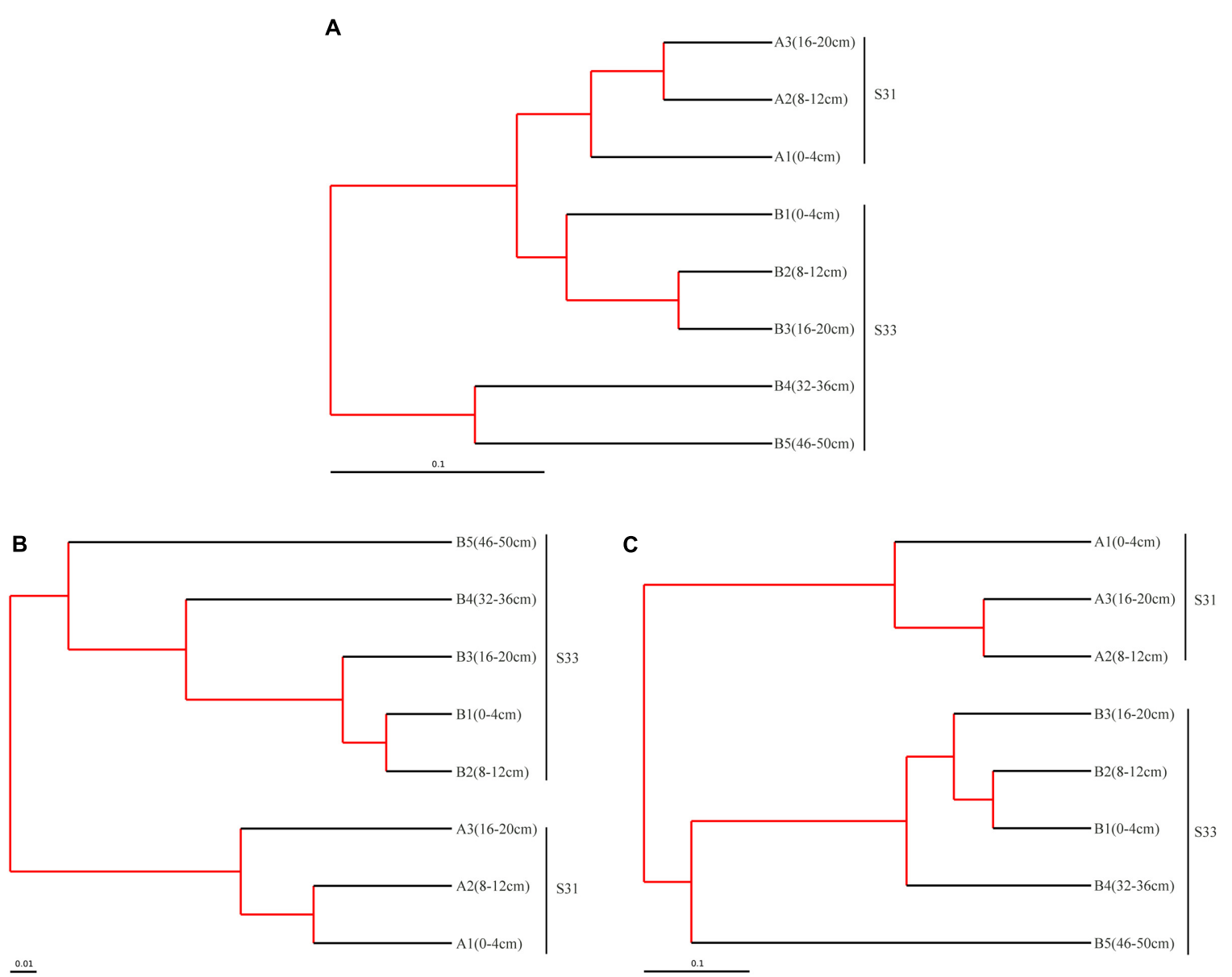

FIGURE 3 | Tree representing the results of the UPGMA hierarchical clustering of the weighted UniFrac distance matrix for the 16S rRNA (A), dsrB (B), and soxB (C) genes in sediments from the ECS. The scale bar indicates the distance between clusters in UniFrac units. The red branch represents $75-100 \%$ level of jackknife support.

Spirochaetes were the second and third most dominant phyla, accounting for 5.32 (two OTUs) and $2.31 \%$ (eight OTUs) of the sequences, respectively (Figure 6). In addition, 238 OTUs representing $20.05-45.82 \%$ of the sequences were unclassified (Figure 6). The dominant Proteobacteria phylum was classified into three classes: Alphaproteobacteria (varying from 31.37 to $53.00 \%$ ), Betaproteobacteria (varying from 1.00 to $14.64 \%$ ), and Gammaproteobacteria (varying from 4.28 to $12.50 \%$ ).
The composition and structure of the SOB community in the various samples were compared at the family level (Figure 7). Bradyrhizobiaceae was the dominant family in all samples and was more abundant (34.72\%) in S31 than in S33 (ranging from 15.79 to $29.86 \%$ ). Four other minor families (Rhodobacteraceae, Hyphomicrobiaceae, Rhodospirillaceae, and an unclassified group) within Alphaproteobacteria were more abundant in S33 than in S31. Among the Betaproteobacteria, Burkholderiaceae,

TABLE 2A | Similarity-based OTUs and species richness and diversity estimates based on the $d s r B$ gene.

\begin{tabular}{|c|c|c|c|c|c|c|}
\hline Station & Depth (cm) & Read number & OTUs & Shannon & Chao 1 & Good's coverage (\%) \\
\hline & $8-12$ & 78,861 & 240 & 3.782 & 266.464 & 99.9 \\
\hline \multirow[t]{3}{*}{ S33 } & $0-4$ & 67,284 & 336 & 2.708 & 343.483 & 99.9 \\
\hline & $8-12$ & 78,034 & 393 & 2.885 & 425.697 & 99.9 \\
\hline & $16-20$ & 76,646 & 456 & 3.247 & 485.94 & 99.9 \\
\hline
\end{tabular}


TABLE 2B | Similarity-based OTUs and species richness and diversity estimates based on the soxB gene.

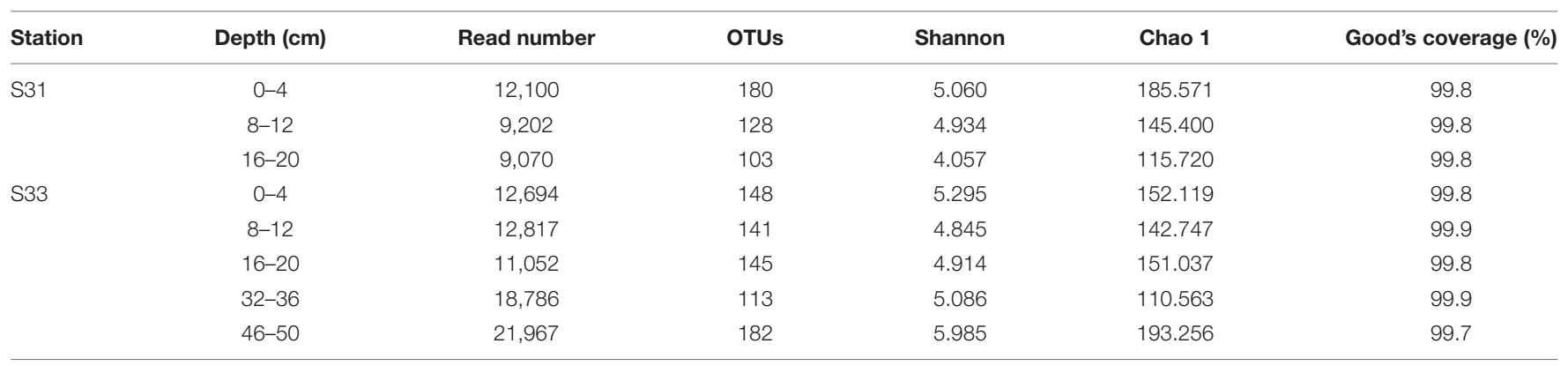

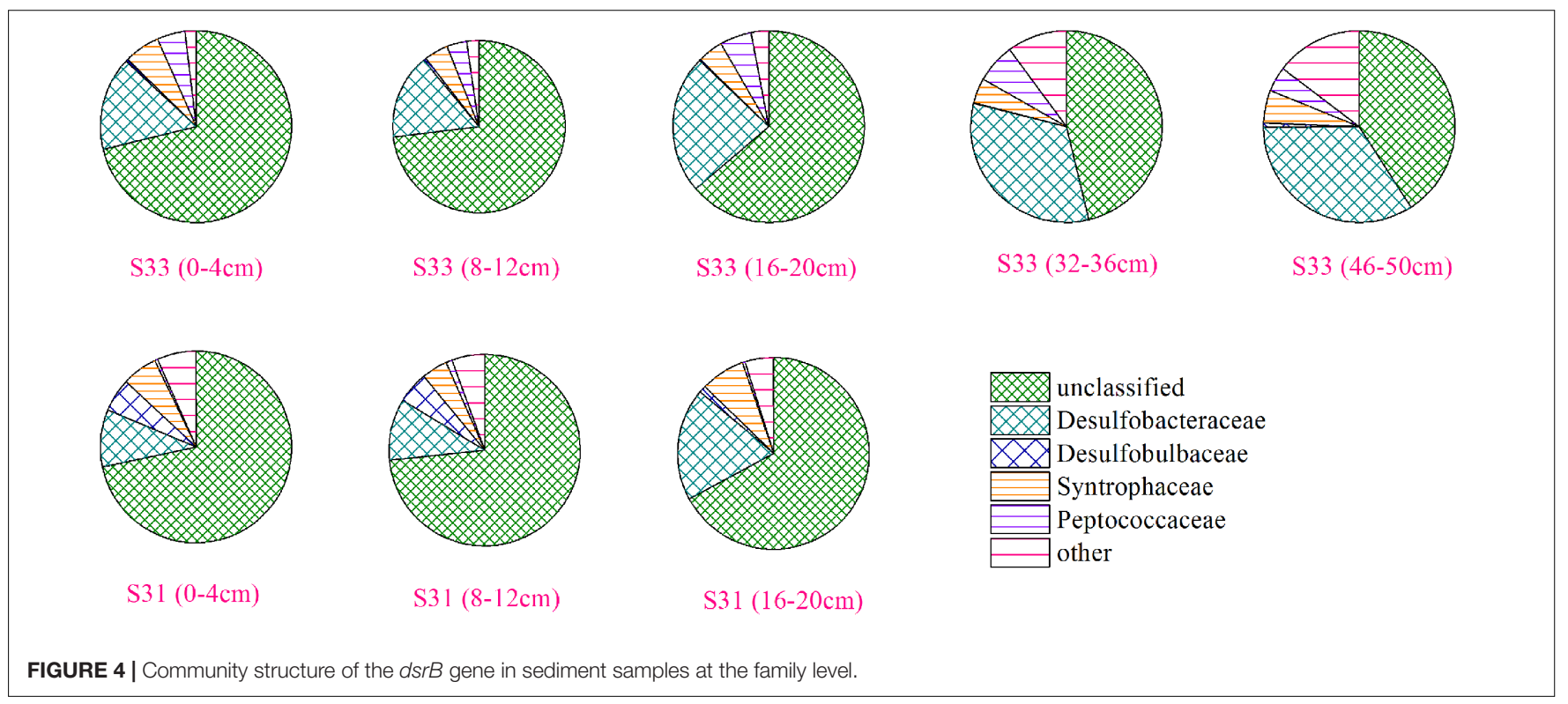

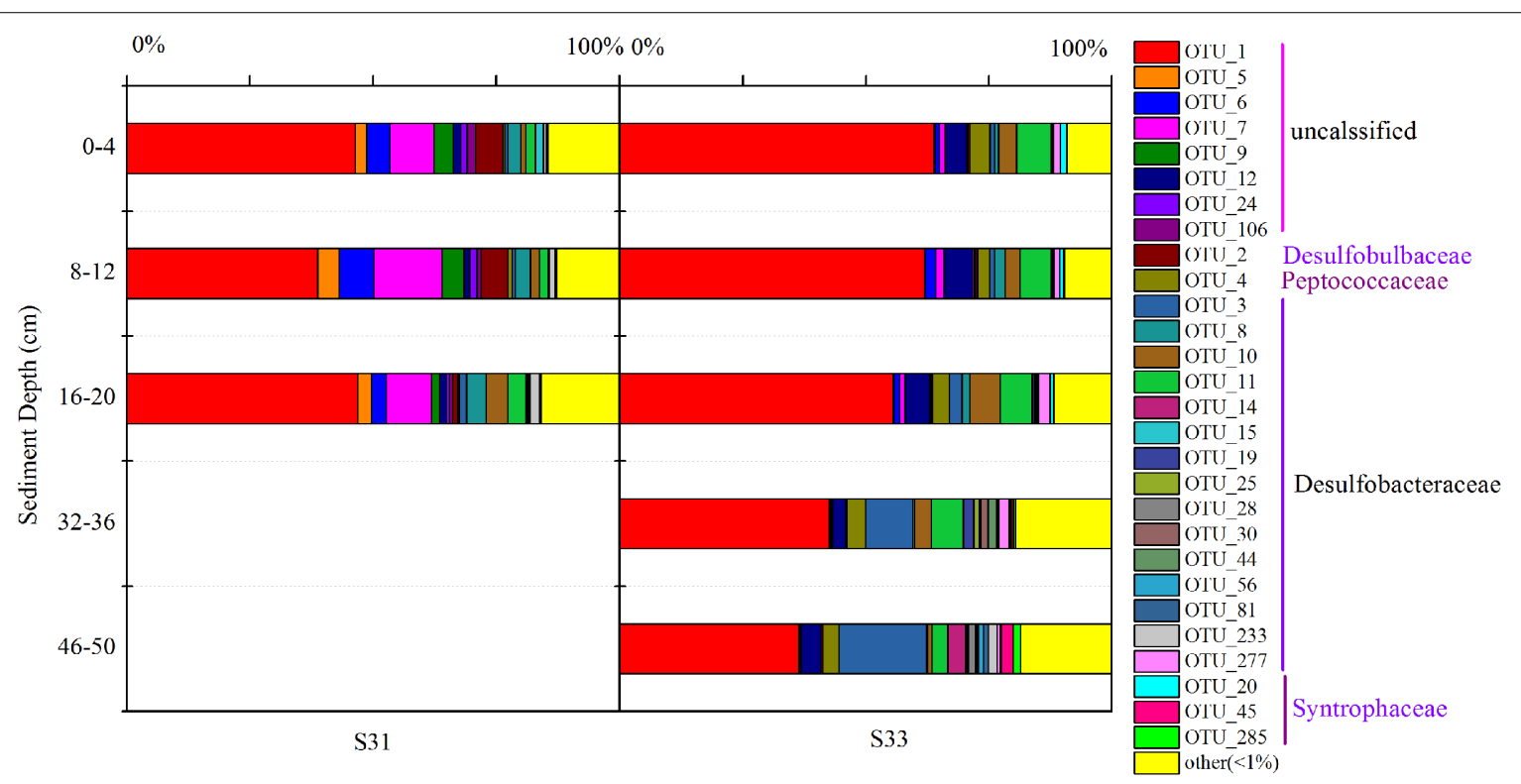

FIGURE 5 | Relative abundance of dominant OTUs (relative abundance > 1\%) of the dsrB gene observed in core samples collected from the East China Sea. 


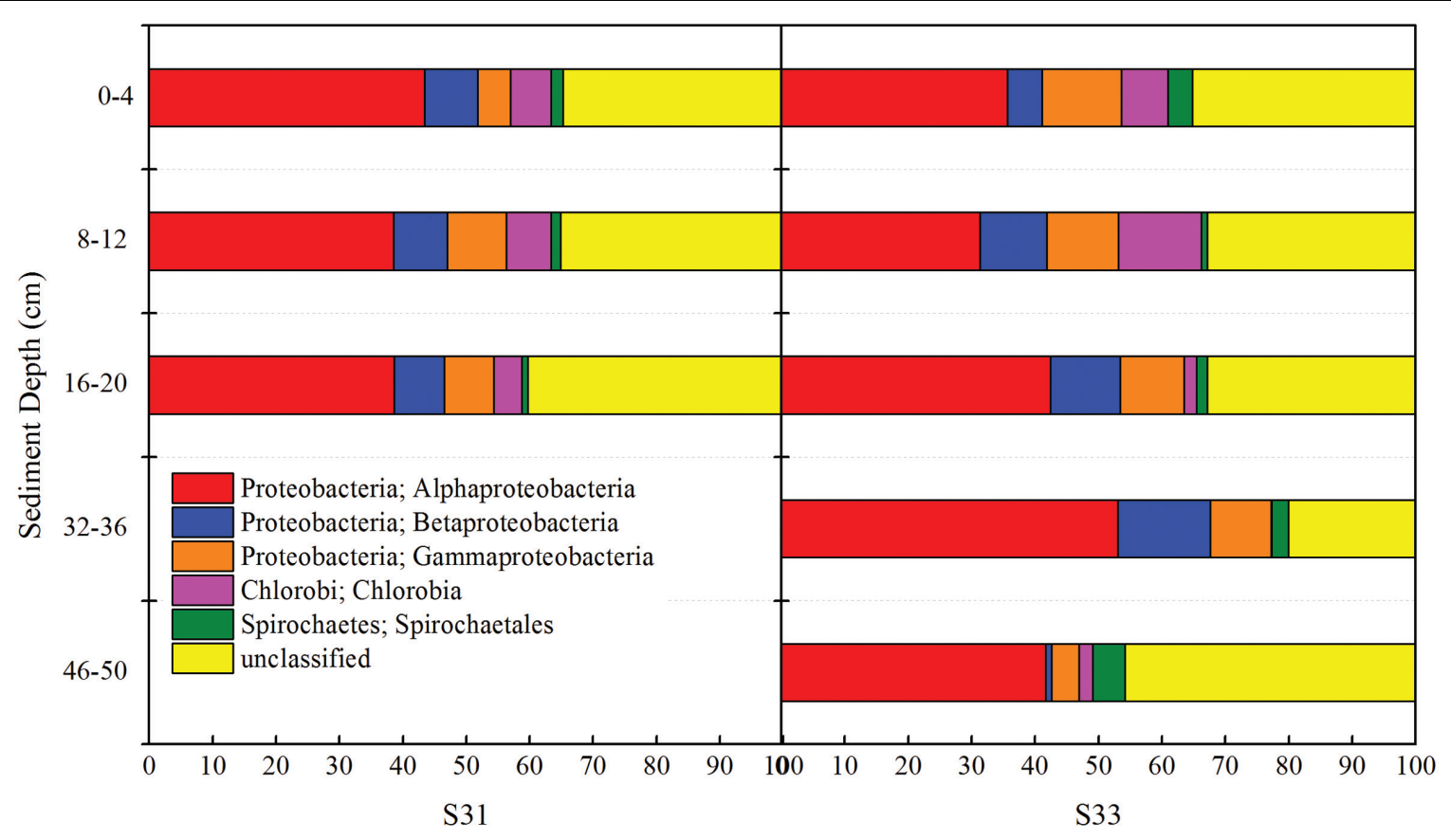

FIGURE 6 | Relative abundance of the soxB gene observed in core samples collected from the East China Sea.

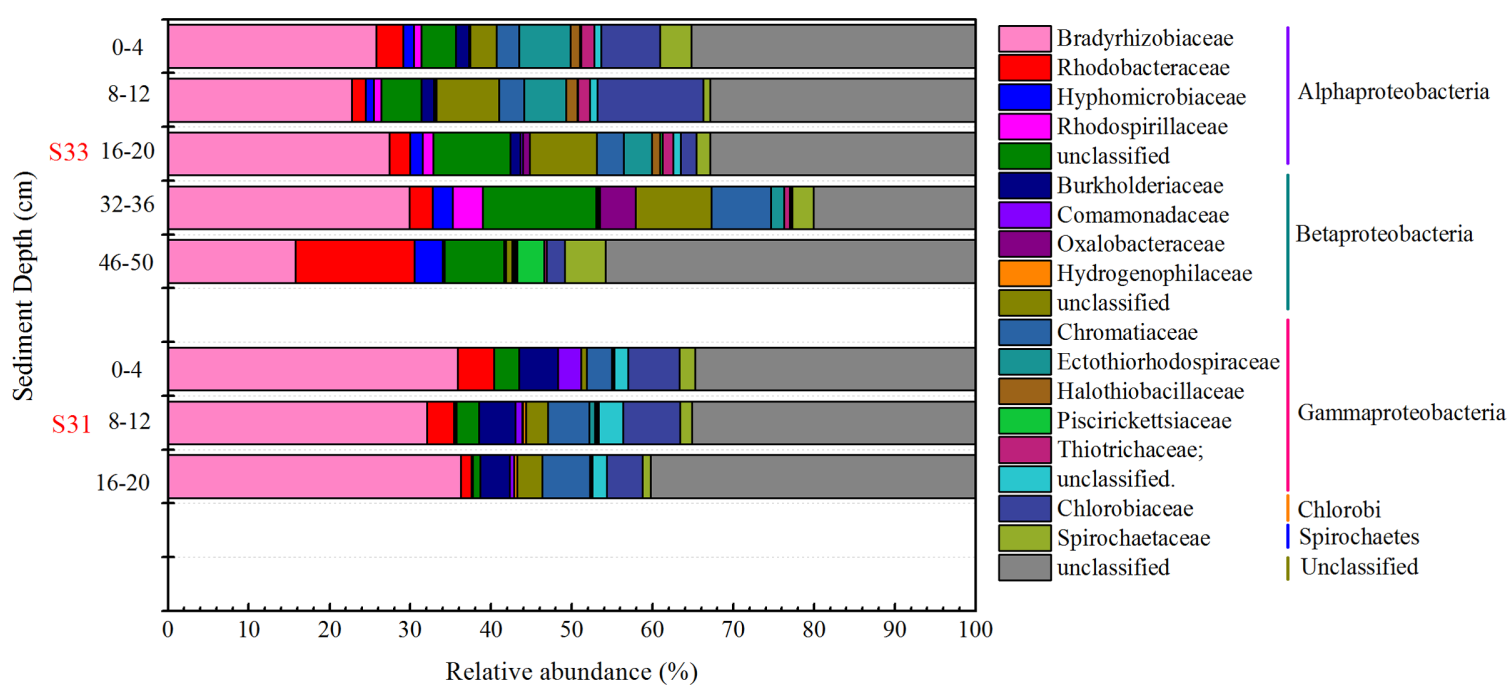

FIGURE 7 | Relative abundance of the soxB gene in the core samples at the family level.

with a relative abundance of $4.31 \%$ (on average), was the dominant family in S31, whereas an unclassified group with a relative abundance of $5.91 \%$ (on average) was the dominant family in S33. Furthermore, within Gammaproteobacteria, Ectothiorhodospiraceae was the dominant family in almost all samples from S33, but its abundance was only $0.11-0.71 \%$ at S31. The UPGMA clustering analysis (Figure 3C) based on the weighted UniFrac distance metric showed that the SOB communities from S31 and S33 clustered separately from each other, further demonstrating the differences in the $\mathrm{SOB}$ community structure between the two sampling stations and among different sediment depths.

\section{Influence of Environmental Variables on Total Bacterial, SRB, and SOB Communities}

BIOENV identified that the environmental factors most strongly correlated with the total bacteria, SRB, and SOB communities were depth, $\mathrm{pH}$, dissolved inorganic nitrogen (DIN), phosphate 


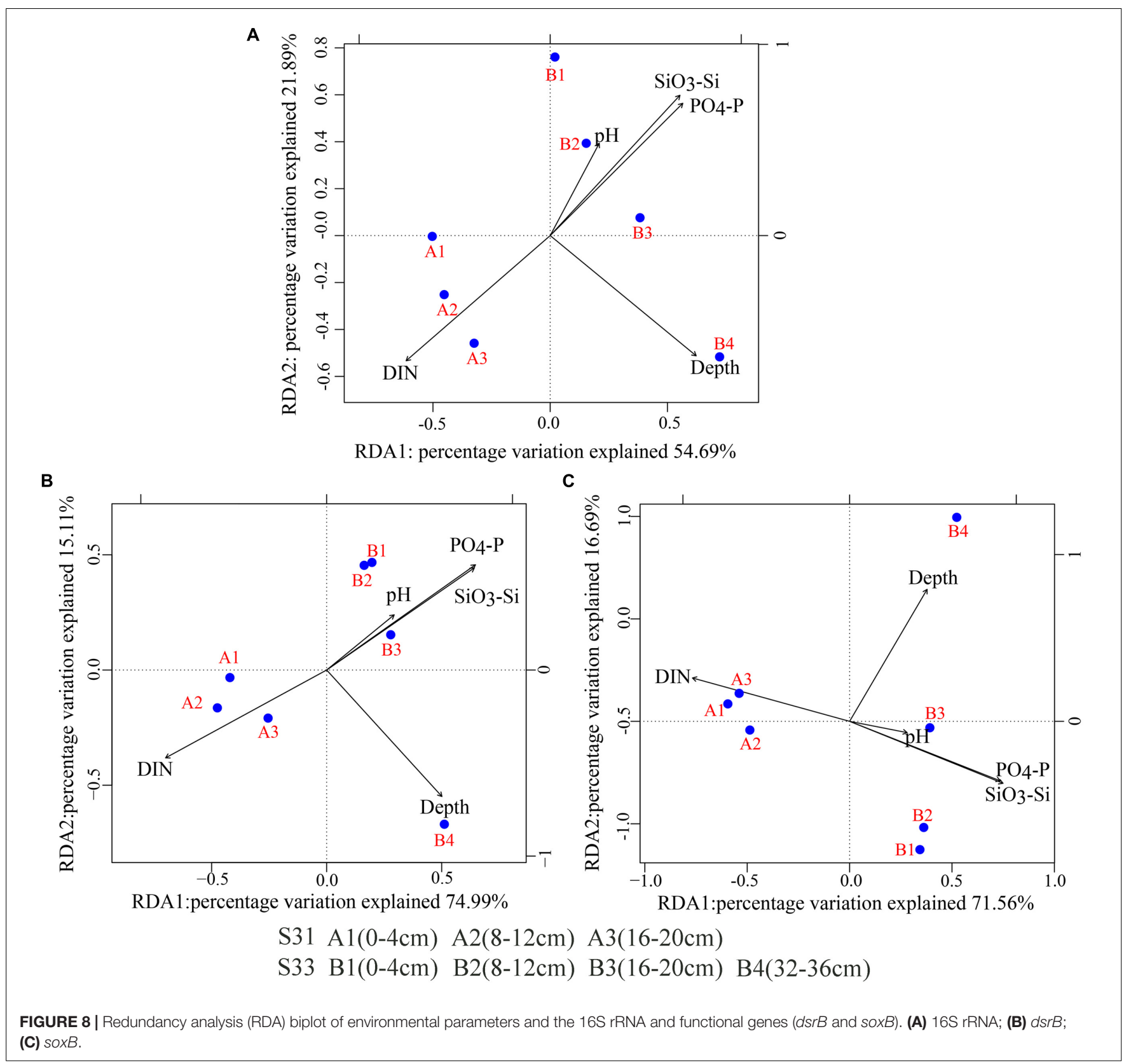

$\left(\mathrm{PO}_{4}-\mathrm{P}\right)$, and silicate $\left(\mathrm{SiO}_{3}-\mathrm{Si}\right)$ (correlation $\left.>0.6\right)$. Together, these variables explained $76.58,90.10$, and $88.25 \%$ of the variation in the bacteria, SRB, and SOB communities, respectively, as determined through RDA (Figure 8). The environmental variables that were found to contribute significantly to the microbial community-environment relationship (900 Monte Carlo permutations) were depth and DIN for all of the examined genes (16S rRNA, $d s r B$ and soxB gene).

\section{Abundance of Total Bacterial 16S rRNA and Functional Genes}

The abundance of total bacterial 16S rRNA and functional genes $(d s r B$ and $s o x B)$ in the $21-$ and $50-\mathrm{cm}$-long core samples from
S31 and S33, respectively, were determined via qPCR (Figure 9). In the core sample from S31, the vertical abundance profile of the $d s r B$, sox $B$, and $16 \mathrm{~S}$ rRNA genes showed marked fluctuations, and the range of fluctuation in the abundances of the 16S rRNA and soxB genes was smaller than that in the abundance of the $d s r B$ gene. However, analysis of the core sample from S33 showed that the abundances of the $d s r B$, $\operatorname{sox} B$, and 16S rRNA genes gradually decreased with increasing depth.

\section{DISCUSSION}

In this study, a comparative analysis of the sulfur cycle-related microbial communities (SRB and SOB) in sediment cores was 


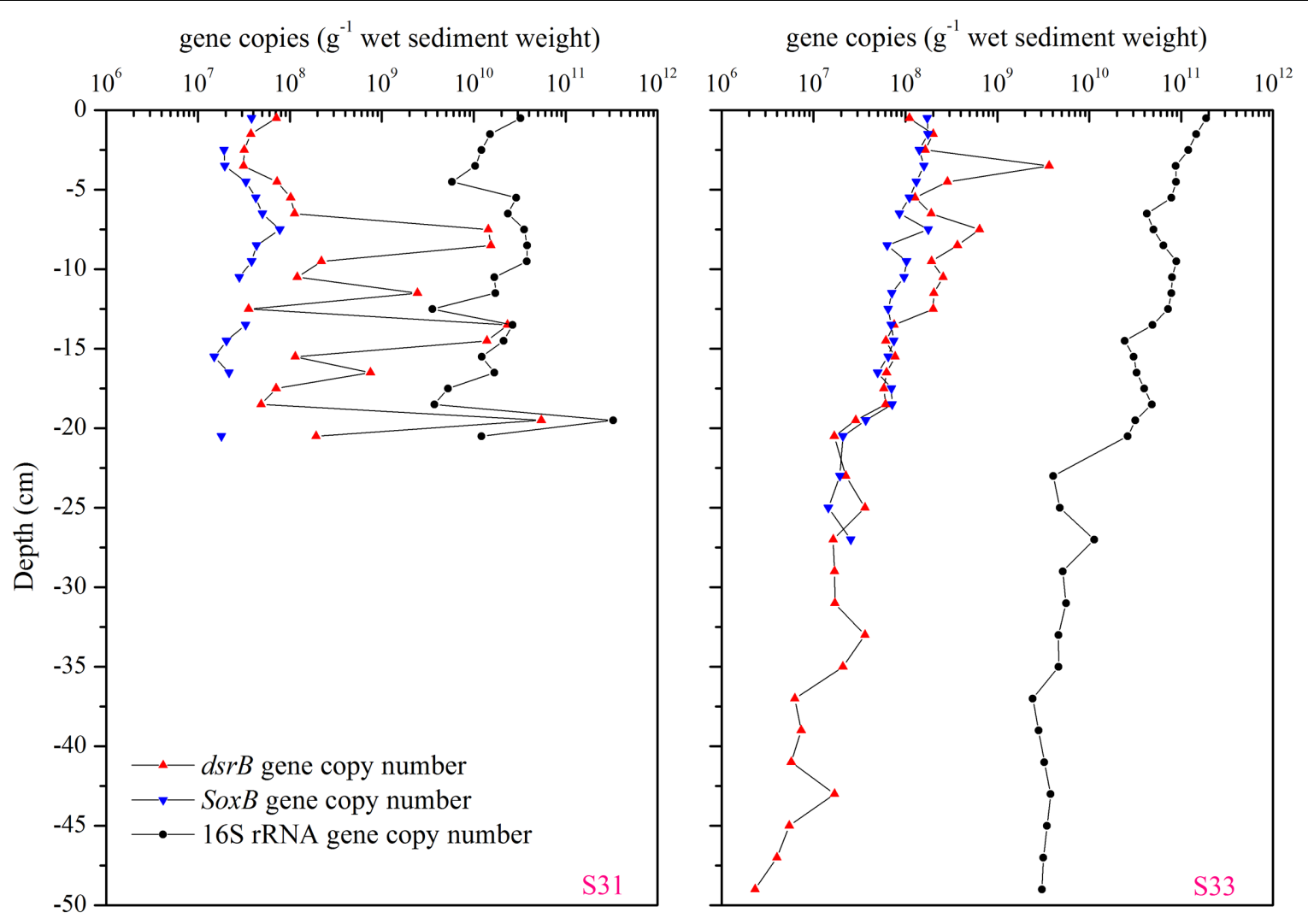

FIGURE 9 | Vertical profiles of the $d s r B$, soxB, and total bacterial 16S rRNA gene copy numbers in the core samples from S31 and S33.

performed using an approach combining $16 \mathrm{~S}$ rRNA, $d s r B$, and soxB gene high-throughput sequencing with qPCR analyses. The combination of these molecular techniques provided a detailed description of the SRB and SOB communities. The traditional approaches (e.g., DGGE and clone library), which have been widely applied for the detection of SRB and SOB in various environments, might notably underestimate their diversity. High-throughput sequencing based on functional genes $(d s r B$ and $s o x B)$ can result in a greater number of sequences and almost complete coverage (Good's coverage values were all greater than 99\%), providing more comprehensive information regarding the diversity and community composition of the SRB and SOB communities. Thus, the diversity, richness and OTU numbers observed in our high-throughput sequencing analyses were notably greater than those obtained in previous studies that employed other molecular methods (Jiang et al., 2009; Yang et al., 2013; Yousuf et al., 2014; He et al., 2015). Further analysis indicated that rare species make important contributions to the greater richness and diversity of the SRB and SOB communities. For instance, as shown in Table $\mathbf{3 A}$, the number of dominant OTUs in each sample was similar, ranging from 8 to 13 and representing $3.08 \%$ of OTUs (on average); however, these OTUs comprised more than $77 \%$ of the sequence abundance for the $d s r B$ gene. Although the rare OTUs (relative abundance $<0.01 \%$ ) (Galand et al., 2009) accounted for 54.03\% of OTUs (on average), they only comprised $0.84 \%$ (on average) of the sequence abundance. Similar results were obtained for the soxB gene (Table 3B).

The 16S rRNA sequencing analysis identified 235 and 191 OTUs as belonging to potential SRB and SOB, respectively, based on family species classification. Furthermore, these SRB OTUs were affiliated with 10 families, accounting for 7.63$19.62 \%(14.12 \%$ on average) of the total $16 \mathrm{~S}$ rRNA gene sequences (Table 4A), and the SOB OTUs were affiliated with 12 families, accounting for $5.99-18.78 \%$ (12.53\% on average) of the total $16 \mathrm{~S}$ rRNA sequences (Table 4B). This finding is consistent with the results of a previous study in this region that found that numerous sequences were affiliated with potential SRB and SOB (Ye et al., 2016). Overall, these results confirm the high abundance of potential SOB and SRB groups in the ECS sediments and suggest the existence of an active sulfur cycle in this area, and these sulfur cycle-related bacterial communities have considerable potential for further exploration.

The $d s r B$ gene sequencing analysis performed in this study identified two phyla (Proteobacteria and Firmicutes), and Deltaproteobacteria (within Proteobacteria) represented the dominant SRB. Our data were consistent with previous observations obtained from various environments, such as marsh sediments (Jemaneh et al., 2013), the Great Salt Lake (Kjeldsen et al., 2007), mangrove sediments (VaronLopez et al., 2013), wastewater treatment plants (Biswas et al., 2014), and marine and estuary sediments (Jiang 
TABLE 3A | Rare and dominant OTUs based on the dsrB gene.

\begin{tabular}{|c|c|c|c|c|c|c|}
\hline Station & Depth (cm) & Total number of OTUs & Dominant OTUs & Abundance of dominant OTUs (\%) & Rare OTUs & Abundance of rare OTUs (\%) \\
\hline \multirow[t]{3}{*}{ S31 } & $0-4$ & 336 & 13 & 83.54 & 183 & 0.78 \\
\hline & $8-12$ & 240 & 12 & 84.23 & 121 & 0.49 \\
\hline & $16-20$ & 322 & 12 & 81.41 & 180 & 0.70 \\
\hline \multirow[t]{5}{*}{ S33 } & $0-4$ & 336 & 8 & 86.84 & 191 & 0.77 \\
\hline & $8-12$ & 393 & 9 & 86.70 & 257 & 1.03 \\
\hline & $16-20$ & 456 & 10 & 85.30 & 287 & 1.23 \\
\hline & $32-36$ & 487 & 11 & 77.16 & 220 & 0.97 \\
\hline & $46-50$ & 413 & 12 & 77.48 & 180 & 0.78 \\
\hline
\end{tabular}

TABLE 3B | Rare and dominant OTUs based on the soxB gene.

\begin{tabular}{|c|c|c|c|c|c|c|}
\hline Station & Depth (cm) & Total number of OTUs & Dominant OTUs & Abundance of dominant OTUs (\%) & Rare OTUs & Abundance of rare OTUs (\%) \\
\hline \multirow[t]{3}{*}{ S31 } & $0-4$ & 180 & 18 & 76.62 & 88 & 4.13 \\
\hline & $8-12$ & 128 & 19 & 78.45 & 47 & 1.76 \\
\hline & $16-20$ & 103 & 14 & 85.06 & 49 & 2.05 \\
\hline \multirow[t]{5}{*}{ S33 } & 0-4 & 148 & 23 & 76.96 & 61 & 2.53 \\
\hline & $8-12$ & 141 & 20 & 80.09 & 59 & 2.69 \\
\hline & $16-20$ & 145 & 21 & 76.78 & 59 & 2.51 \\
\hline & $32-36$ & 113 & 22 & 80.58 & 26 & 1.22 \\
\hline & $46-50$ & 182 & 30 & 67.58 & 50 & 1.72 \\
\hline
\end{tabular}

et al., 2009; Wu et al., 2009; He et al., 2015), suggesting that Deltaproteobacteria have a wide adaptation range and play major roles in global sulfur cycling. The soxB gene sequencing results revealed that the SOB community was dominated by Alphaproteobacteria and unclassified groups, followed by Gammaproteobacteria and Betaproteobacteria. For comparison, Gammaproteobacteria and Epsilonproteobacteria are considered dominant Sox organisms in marine sediments (Sievert et al., 2008; Lenk et al., 2011; Akerman et al., 2013; Dyksma et al., 2016); however, no Epsilonproteobacteria groups were observed in the present study. This discrepancy could be due to primer bias; the primers used for soxB gene amplification amplify the $s o x B$ genes of Epsilonproteobacteria and Chloroflexi very poorly (Meyer and Kuever, 2007). In addition, Bradyrhizobiaceae within Alphaproteobacteria and Burkholderiaceae within Betaproteobacteria were the dominant families in our study area; however, previous research revealed that these families might adapt to oligotrophic sulfur environments, such as soil (Jung et al., 2005; Masuda et al., 2010) and rhizosphere soils (Anandham et al., 2008; Masuda et al., 2016). Therefore, further study is required to determine whether the families described here are the result of contamination or actually exist. More interestingly, most of the domain and core OTUs obtained through $\operatorname{ds} r B$ and $\operatorname{soxB}$ gene high-throughput sequencing were difficult to clearly assign at the family or genus level, partially due to the limited number of reference sequences. For instance, 15 OTUs for the $d s r B$ gene, with a relative abundance ranging from 40.91 to $73.36 \%$, and 238 OTUs for the $s o x B$ gene, with a relative abundance ranging from 20.05 to $45.82 \%$, could not be assigned at the family or genus level. Overall, these findings suggest that the ECS environment contains a high abundance of yet unknown SRB and SOB lineages, which should be studied in more detail. Indeed, this phenomenon is consistent with the following recent findings: $62 \%$ of $d s r B$ sequences in surface sediments from the ECS exhibit low similarity with previously cultured SRB (Zhang et al., 2016); $57.6 \%$ of $d s r A B$ clones from polluted harbor sediments belong to unclassified groups of SRB (Zhang et al., 2008); and 60\% of sequences obtained through a $d s r A$ gene analysis show no clear affiliation with a known SRB (Quillet et al., 2012). Furthermore, similar results have been reported by Yousuf et al. (2014) for soxB. In addition, we noticed that these unclassified OTUs exhibit high similarity with environmental $d s r B /$ soxB sequences, as demonstrated through BLAST identity searches. For example, most of the unclassified $d s r B$ OTUs displayed high similarities (>90\%) with uncultured SRB recovered from Japanese fish farm sediments (Kondo et al., 2012) and ECS sediments (He et al., 2015; Zhang et al., 2016). Similarly, most of the unclassified soxB sequences exhibited high similarity (>80\%) with sequences recovered from coastal soil ecosystems (Yousuf et al., 2014). These observations suggest that these unclassified sequences are widely distributed in marine and terrestrial environments and play a vital role in the biogeochemical cycling of sulfur and carbon.

A comparison of the SRB community composition identified based on the 16S rRNA and $d s r B$ genes showed that $16 \mathrm{~S}$ rRNA gene sequencing detected 10 SRB families, whereas $d s r B$ gene sequencing only detected four SRB families (Tables 4A,B). Moreover, it was difficult to obtain more detailed taxonomic information for the SRB community based on the 16S rRNA and $d s r B$ genes. Overall, the $d s r B$ gene proved to be less efficient for the proper annotation of taxonomic information for SRB groups. This phenomenon might be attributed to the limited number of reference sequences used to annotate taxonomic information for 
the $d s r B$ gene. In contrast, the results obtained from the highthroughput sequencing of the soxB gene revealed 15 SOB families, whereas the high-throughput sequencing of the 16S rRNA gene revealed 12 SOB families. In addition, the sox $B$ gene can provide more detailed taxonomic information (at the genus or even the species level) for the SOB community (data not shown) than the $16 \mathrm{~S}$ rRNA gene. Taken together, the results indicate that the soxB gene might better define SOB groups.

The 16S rRNA, $d s r B$ and soxB gene high-throughput sequencing data obtained in the present study revealed a high diversity of SRB and SOB in sediments from the ECS, and the classification of SRB and SOB communities based on 16S rRNA

TABLE 4A | SRB community composition based on taxonomic information of the dsrB and 16S rRNA genes.

\begin{tabular}{lcccc}
\hline Family level & \multicolumn{3}{c}{ OTUs } & \multicolumn{3}{c}{ Total abundance (\%) } \\
\cline { 2 - 5 } & 16S rRNA & dsrB & 16S rRNA & dsrB \\
\hline Peptococcaceae & 6 & 6 & $0-0.33$ & $0.45-6.60$ \\
Desulfobacteraceae & 51 & 42 & $1.26-4.97$ & $9.60-34.05$ \\
Desulfobulbaceae & 38 & 4 & $0.27-9.37$ & $0.11-5.67$ \\
Syntrophaceae & 6 & 42 & $0.007-0.34$ & $4.23-7.50$ \\
Nitrosomonadaceae & 1 & - & $0.01-0.62$ & - \\
Desulfarculaceae & 26 & - & $0.32-5.82$ & - \\
Desulfovibrionaceae & 1 & - & $0-0.01$ & - \\
Syntrophobacteraceae & 52 & - & $0.13-0.77$ & - \\
Nitrospiraceae & 12 & - & $0.10-1.16$ & - \\
Thermodesulfovibrionaceae & 42 & - & $1.72-8.59$ & - \\
\hline
\end{tabular}

-, Not detected.

TABLE 4B | SOB community composition based on taxonomic information of the SOXB and 16S rRNA genes.

\begin{tabular}{lccccc}
\hline Family level & \multicolumn{2}{c}{ OTUs } & \multicolumn{2}{c}{ Total abundance (\%) } \\
\cline { 2 - 3 } \cline { 5 - 6 } & 16S rRNA & soxB & & 16S rRNA & soxB \\
\hline Spirochaetaceae & 30 & 8 & & $0.03-0.69$ & $0.85-5.04$ \\
Chlorobiaceae & - & 2 & - & $0.13-13.08$ \\
Helicobacteraceae & 5 & - & & $0.02-4.57$ & - \\
Rhodospirillaceae & 42 & 5 & & $0.24-1.43$ & $0.12-3.75$ \\
Rhodobacteraceae & 27 & 20 & & $0.27-3.32$ & $1.33-14.74$ \\
Bradyrhizobiaceae & 1 & 35 & $0-0.01$ & $15.79-36.26$ \\
Hyphomicrobiaceae & 16 & 2 & $1.38-2.67$ & $0.01-3.51$ \\
Rhizobiaceae & 1 & - & $0-0.01$ & - \\
Neisseriaceae & 1 & - & $0-0.03$ & - \\
Comamonadaceae & 7 & 3 & $0.02-0.15$ & $0.05-2.88$ \\
Ectothiorhodospiraceae & 10 & 2 & $0.07-0.56$ & $0.09-6.38$ \\
Thiotrichaceae & 7 & 2 & $0-0.07$ & $0.06-1.60$ \\
Piscirickettsiaceae & 44 & 4 & $0.52-13.67$ & $0-3.38$ \\
Burkholderiaceae & - & 6 & - & $0.13-4.82$ \\
Oxalobacteraceae & - & 1 & & $0-4.36$ \\
Hydrogenophilaceae & - & 1 & - & $0-0.44$ \\
Chromatiaceae & - & 18 & - & $0.25-7.39$ \\
Halothiobacillaceae & - & 2 & - & $0-1.42$ \\
\hline - Not detected & & & &
\end{tabular}

gene and functional gene was analyzed and compared according to the results of a previous study (Meyer et al., 2016). Overall, the present study provided more comprehensive information regarding the $\mathrm{SRB}$ and $\mathrm{SOB}$ community characteristics and suggested the existence of an active sulfur cycle in the study area. Significantly, the sulfate amount never decreases below approximately $24 \mathrm{mM}$ in the core samples, which appears to contradict the conclusion that SRB and SOB communities are responsible for active sulfur cycling. In fact, this phenomenon will be observed based on the fact that the sulfate consumed by sulfate reduction is recycled within sediments by oxidation of reduced inorganic sulfur compounds to sulfate. As previously reported, $80-95 \%$ of the massive amount of hydrogen sulfide formed through sulfate reduction is recycled within sediments and gradually oxidized back to sulfate (Jørgensen et al., 1990; Jørgensen and Nelson, 2004). Jørgensen et al. (1990) reported that sulfate reduction rates increased in the top $10 \mathrm{~cm}$ of core in the Belt Sea; however, the concentration of sulfate varied little (approximately $25 \mathrm{mM}$ ). Similarly, Leloup et al. (2009) revealed that substantial sulfate reduction rates were measured in the top $25 \mathrm{~cm}$ of core, and the sulfate concentration profile was approximately $20 \mathrm{mM}$. However, the diversity of sulfur cyclerelated bacteria and the potential sulfur cycle activity might still be overestimated or underestimated because certain named $\mathrm{SRB} / \mathrm{SOB}$ might did not actually take part in the sulfur cycle in sediments, such as Pelotomaculum and Sporotomaculum, which are not able to grow with sulfite and/or sulfate as electron acceptors even though they are closely affiliated with SRB (Brauman et al., 1998; Imachi et al., 2006). Instead, certain unnamed SRB/SOB, such as archaeal anaerobic methanotrophs, might be involved in the sulfur cycle in sediments (Treude et al., 2014). Fortunately, these groups are only found in special habitats and account for a small portion of the identified communities (Brauman et al., 1998; Imachi et al., 2006; Miyashita et al., 2009; Treude et al., 2014). Thus, the use of $16 \mathrm{~S}$ rRNA and functional genes $(d s r B$ and $s o x B)$ as proxies for determining the microbial groups that play active roles in sulfur cycling and for studying the diversity of SOB and SRB is a powerful approach.

The sediment environments of the ECS are highly heterogeneous (Dang et al., 2008; Fang et al., 2013); this characteristic has a strong influence on the spatial heterogeneity of the sediment microbial communities in the ECS, as observed in previous studies (Dang et al., 2008; Feng et al., 2009; Chen et al., 2014; Ye et al., 2016). Based on the sediment grain size combined with the overlying water masses, the ECS can be divided into three domains: the inner shelf mud area, the outer shelf sand area, and the slope plus Okinawa Trough mud area (Liu et al., 2006; Xu et al., 2016). S31 is located within the inner shelf mud deposits along the Zhejiang coast, whereas S33 is located at the periphery of the Zhejiang coastal mud area (Supplementary Figure S1). Thus, most of the environmental parameters showed substantial variation among the different samples and among the various sediment depths (Supplementary Table S1 and Figure S2). The concentration of DIN, for instance, ranged from 91.44 to $449.21 \mu \mathrm{M}$ in station S31 and from 18.81 to $120.73 \mu \mathrm{M}$ in station S33 (Supplementary Table S2). ${ }^{210} \mathrm{~Pb}$ has been proven to serve as an effective proxy for sedimentary 
dynamics processes, such as erosion-transportation-deposition, boundary scavenging, and resuspension process, in coastal and shelf regions (Huh and Su, 1999; Su and Huh, 2002). The excess ${ }^{210} \mathrm{~Pb}$ activity varied markedly between the two sediments (Supplementary Figure S2). At station $\mathrm{S} 31,{ }^{210} \mathrm{~Pb}_{\mathrm{ex}}$ activity was stable from the surface sediment to a depth of $8 \mathrm{~cm}$; however, at a depth below $12 \mathrm{~cm},{ }^{210} \mathrm{~Pb}_{\mathrm{ex}}$ activity increased gradually and displayed characteristics of reverse accumulation, indicating that this sedimentary layer has experienced sedimentary dynamic events. At station $\mathrm{S} 33,{ }^{210} \mathrm{~Pb}_{\mathrm{ex}}$ activity remained stable until a depth of $5 \mathrm{~cm}$ and then gradually declined. This finding indicates that the sedimentary dynamic environment at S33 was more stable than that at S31, as observed in our previous study ( $\mathrm{He}$ et al., 2015). Our results showed that the abundances of $16 \mathrm{~S}$ rRNA, $d s r B$ and $s o x B$ genes show substantial fluctuations at S31 (Figure 9), and none of the gene abundance values were significantly correlated with sediment depth. In contrast, all of the genes (16S rRNA, $d s r B$ and $s o x B$ ) gradually decreased with increasing depth at S33 (Figure 9) and were significantly negatively correlated with sediment depth. These results suggest that the sedimentary dynamic environment is likely an important factor in controlling the vertical distribution of the abundances of total bacterial 16S rRNA gene and functional genes ( $d s r B$ and $s o x B$ ). Further analysis revealed similar vertical fluctuations in the abundance of the 16S rRNA, $d s r B$ and $s o x B$ genes at S31, but the range of fluctuation obtained for the abundance of the $16 \mathrm{~S}$ rRNA and $\operatorname{sox} B$ genes was smaller than that observed for the $d s r B$ gene. In addition, the ratios of the functional genes ( $d s r B$ and $s o x B$ ) to the total bacterial $16 \mathrm{~S}$ rRNA gene were calculated: for the $d s r B$ gene, the ratio ranged from 0.22 to $40.56 \%$ in S31 and from 0.06 to $4.2 \%$ in $\mathrm{S} 33$, and the ratios calculated for the $\operatorname{soxB}$ gene were less than $1 \%$ at both stations. These results indicate that the abundance of SRB might be more sensitive to the sedimentary dynamic environment than that of SOB and total bacteria.

The UPGMA clustering analysis results demonstrated different community structures of total bacteria, SRB, and SOB at the two sampling sites and among the different sediment depths, which might be due to the differences in the sediment depths and sedimentary dynamic environments between the two sampling stations. Overall, the sedimentary dynamic environment is most likely related to unmeasured variables, such as salinity, organic matter, dissolved oxygen, temperature, and $\mathrm{H}_{2} \mathrm{~S}$, which are widely accepted as important factors in controlling the community

\section{REFERENCES}

Akerman, N. H., Butterfield, D. A., and Huber, J. A. (2013). Phylogenetic diversity and functional gene patterns of sulfur-oxidizing subseafloor Epsilonproteobacteria in diffuse hydrothermal vent fluids. Front. Microbiol. 4:185. doi: 10.3389/fmicb.2013.00185

Anandham, R., Indiragandhi, P., Madhaiyan, M., Ryu, K. Y., Jee, H. J., and Sa, T. M. (2008). Chemolithoautotrophic oxidation of thiosulfate and phylogenetic distribution of sulfur oxidation gene $(\operatorname{sox} \mathrm{B})$ in rhizobacteria isolated from crop plants. Res. Microbiol. 159, 579-589. doi: 10.1016/j.resmic.2008.08.007

Aoki, M., Kakiuchi, R., Yamaguchi, T., Takai, K., Inagaki, F., and Imachi, H. (2015). Phylogenetic diversity of aprA genes in subseafloor sediments on the northwestern Pacific margin off Japan. Microbes Environ. 30, 276-280. doi: 10.1264/jsme2.ME15023 structures of total bacteria and sulfur-cycling bacteria (SRB and SOB) (Headd and Engel, 2013; Ye et al., 2016; Zhang et al., 2016). In addition, an RDA analysis revealed that sediment depth and DIN have a significant influence on the community structure of total bacteria, SRB, and SOB. In summary, our results suggest that environmental parameters, such as sediment depth and DIN, and the sedimentary dynamic environment, which showed differences between the two sampling stations, can significantly influence the community structure of total bacteria, $\mathrm{SRB}$, and SOB.

\section{AUTHOR CONTRIBUTIONS}

YZhe, TM, and ZY conceived and designed the experiments; YZha, XW, and HH performed the experiments and analyzed the data; YZha and YZhe wrote the paper.

\section{FUNDING}

This work was supported by the National Natural Science Foundation of China (Nos. 41620104001 and 41521064), the Scientific and Technological Innovation Project of the Qingdao National Laboratory for Marine Science and Technology (2016ASKJ02) and the Open Fund of Key Laboratory of Marine Ecology and Environmental Sciences, Institute of Oceanology, Chinese Academy of Sciences, and Laboratory of Marine Ecology and Environmental Science, Qingdao National Laboratory for Marine Science and Technology (KLMEES201601).

\section{ACKNOWLEDGMENT}

We are grateful to all staff at Run-Jiang for the assistance provided in the collection of samples and geochemical data during the cruise.

\section{SUPPLEMENTARY MATERIAL}

The Supplementary Material for this article can be found online at: https://www.frontiersin.org/articles/10.3389/fmicb. 2017.02133/full\#supplementary-material

Beardsley, R. C., Limeburner, R., Yu, H., and Cannon, G. A. (1985). Discharge of the Changjiang (Yangtze River) into the East China Sea. Cont. Shelf Res. 4, 57-76. doi: 10.1016/0278-4343(85)90022-6

Biswas, K., Taylor, M. W., and Turner, S. J. (2014). dsrAB-based analysis of sulphate-reducing bacteria in moving bed biofilm reactor (MBBR) wastewater treatment plants. Appl. Microbiol. Biotechnol. 98, 7211-7222. doi: 10.1007/ s00253-014-5769-5

Bowles, M. W., Mogollón, J. M., Kasten, S., Zabel, M., and Hinrichs, K. (2014). Global rates of marine sulfate reduction and implications for sub-sea-floor metabolic activities. Science 344, 889-891. doi: 10.1126/science.1249213

Brauman, A., Müller, J. A., Garcia, J. L., Brune, A., and Schink, B. (1998). Fermentative degradation of 3-hydroxybenzoate in pure culture by a novel strictly anaerobic bacterium, Sporotomaculum hydroxybenzoicum gen. nov. sp. nov. Int. J. Syst. Bacteriol. 48, 215-221. doi: 10.1099/00207713-48-1-215 
Caporaso, J. G., Kuczynski, J., Stombaugh, J., Bittinger, K., Bushman, F. D., Costello, E. K., et al. (2010). QIIME allows analysis of high-throughput community sequencing data. Nat. Methods 7, 335-336. doi: 10.1038/nmeth. f.303

Chen, Y. Y., Zhen, Y., He, H., Lu, X. L., Mi, T. Z., and Yu, Z. G. (2014). Diversity, abundance, and spatial distribution of ammonia-oxidizing $\beta$-proteobacteria in sediments from Changjiang estuary and its adjacent area in East China Sea. Microb. Ecol. 67, 788-803. doi: 10.1007/s00248-013-0341-x

Cheng, F., Song, X., Yu, Z., and Liu, D. (2012). Historical records of eutrophication in Changjiang (Yangtze) River estuary and its adjacent East China Sea. Biogeosci. Discuss 9, 6261-6291. doi: 10.5194/bgd-9-6261-2012

Cui, J., Chen, X. P., Nie, M., Fang, S. B., Tang, B. P., Quan, Z. X., et al. (2017). Effects of Spartina alterniflora invasion on the abundance, diversity, and community structure of sulfate reducing bacteria along a successional gradient of coastal salt marshes in China. Wetlands 37, 221-232. doi: 10.1007/s13157-016-0860-6

Dang, H. Y., Li, J., Chen, R. P., Wang, L., Guo, L. Z., Zhang, Z. N., et al. (2010). Diversity, abundance, and spatial distribution of sediment ammoniaoxidizing Betaproteobacteria in response to environmental gradients and coastal eutrophication in Jiaozhou Bay, China. Appl. Environ. Microbiol. 76, 4691-4702. doi: 10.1128/AEM.02563-09

Dang, H. Y., Zhang, X. X., Sun, J., Li, T. G., Zhang, Z. N., and Yang, G. P. (2008). Diversity and spatial distribution of sediment ammonia-oxidizing crenarchaeota in response to estuarine and environmental gradients in the Changjiang Estuary and East China Sea. Microbiology 154, 2084-2095. doi: 10.1099/mic.0.2007/013581-0

Dyksma, S., Bischof, K., Fuchs, B. M., Hoffmann, K., Meier, D., Meyerdierks, A., et al. (2016). Ubiquitous Gammaproteobacteria dominate dark carbon fixation in coastal sediments. ISME J. 10, 1939-1953. doi: 10.1038/ISMEJ.2015.257

Edgar, R. C. (2013). UPARSE: highly accurate OTU sequences from microbial amplicon reads. Nat. Methods 10, 996-998. doi: 10.1038/nmeth.2604

El-Chakhtoura, J., Prest, E., Saikaly, P., Loosdrecht, M. V., Hammes, F., and Vrouwenvelder, H. (2015). Dynamics of bacterial communities before and after distribution in a full-scale drinking water network. Water Res. 74, 180-190. doi: 10.1016/j.watres.2015.02.015

Fang, Z. M., Yang, W. F., Zhang, X. X., Chen, M., Fan, D. J., Ma, Q., et al. (2013). Sedimentation and lateral transport of $210 \mathrm{~Pb}$ over the East China Sea Shelf. J. Radioanal. Nucl. Chem. 298, 739-748. doi: 10.1007/s10967-013-2561-4

Feng, B. W., Li, X. R., Wang, J. H., Hu, Z. Y., Meng, H., Xiang, L. Y., et al. (2009). Bacterial diversity of water and sediment in the Changjiang Estuary and coastal area of the East China Sea. FEMS Microbiol. Ecol. 70, 80-92. doi: 10.1111/j.1574-6941.2009.00772.x

Foti, M., Sorokin, D. Y., Lomans, B., Mussman, M., Zacharova, E. E., Pimenov, N. Y., et al. (2007). Diversity, activity, and abundance of sulfate-reducing bacteria in saline and hypersaline soda lakes. Appl. Environ. Microbiol. 73, 2093-2100. doi: 10.1128/AEM.02622-06

Galand, P. E., Casamayor, E. O., Kirchman, D. L., and Lovejoy, C. (2009). Ecology of the rare microbial biosphere of the Arctic Ocean. Proc. Natl. Acad. Sci. U.S.A. 106, 22427-22432. doi: 10.1073/pnas.0908284106

Geets, J., Borremans, B., Diels, L., Springael, D., Vangronsveld, J., van der Lelie, D., et al. (2006). DsrB gene-based DGGE for community and diversity surveys of sulfate-reducing bacteria. J. Microbiol. Methods 66, 194-205. doi: 10.1016/ j.mimet.2005.11.002

Ghosh, W., and Dam, B. (2009). Biochemistry and molecular biology of lithotrophic sulfur oxidation by taxonomically and ecologically diverse bacteria and archaea. FEMS Microbiol. Rev. 33, 999-1043. doi: 10.1111/j.1574-6976. 2009.00187.x

He, H., Zhen, Y., Mi, T. Z., Xu, B. C., Wang, G. S., Zhang, Y., et al. (2015). Community composition and distribution of sulfate-and sulfite-reducing prokaryotes in sediments from the Changjiang Estuary and adjacent East China Sea. Estuar. Coast. Shelf Sci. 165, 75-85. doi: 10.1016/j.ecss.2015.09.005

Headd, B., and Engel, A. S. (2013). Evidence for niche partitioning revealed by the distribution of sulfur oxidation genes collected from areas of a terrestrial sulfidic spring with differing geochemical conditions. Appl. Environ. Microbiol. 79, 1171-1182. doi: 10.1128/AEM.02812-12

Hernández-Landa, R. C., Acosta-González, G., Núñez-Lara, E., and AriasGonzález, J. E. (2015). Spatial distribution of surgeonfish and parrotfish in the north sector of the mesoamerican barrier reef system. Mar. Ecol. 36, 432-446. doi: $10.1111 /$ maec. 12152
Huh, C. A., and Su, C. C. (1999). Sedimentation dynamics in the East China Sea elucidated from 210Pb, 137Cs and 239,240Pu. Mar. Geol. 160, 183-196.

Imachi, H., Sekiguchi, Y., Kamagata, Y., Loy, A., Qiu, Y. L., Hugenholtz, P., et al. (2006). Non-sulfate-reducing, syntrophic bacteria affiliated with Desulfotomaculum cluster I are widely distributed in methanogenic environments. Appl. Environ. Microbiol. 72, 2080-2091. doi: 10.1128/AEM.72. 3.2080-2091.2006

Jemaneh, Z., Qiang, S., Wang, J. G., Huang, M. Y., Xia, F., Wu, J. H., et al. (2013). Effects of Spartina alterniflora invasion on the communities of methanogens and sulfate-reducing bacteria in estuarine marsh sediments. Front. Microbiol. 4:243. doi: 10.3389/fmicb.2013.00243

Jiang, L. J., Zheng, Y. P., Peng, X. T., Zhou, H. Y., Zhang, C. L., Xiao, X., et al. (2009). Vertical distribution and diversity of sulfate-reducing prokaryotes in the Pearl River estuarine sediments, Southern China. FEMS Microbiol. Ecol. 70, 249-262. doi: 10.1111/j.1574-6941.2009.00758.x

Jiao, N. Z., Yang, Y. H., Hong, N., Ma, Y., Harada, S., Koshikawa, H. S., et al. (2005). Dynamics of autotrophic picoplankton and heterotrophic bacteria in the East China Sea. Cont. Shelf Res. 25, 1265-1279. doi: 10.1016/j.csr.2005. 01.002

Jørgensen, B. B. (1982). Mineralization of organic matter in the sea bed-the role of sulphate reduction. Nature 296, 643-645. doi: 10.1038/296643a0

Jørgensen, B. B., Bang, M., and Blackburn, T. H. (1990). Anaerobic mineralization in marine sediments from the Baltic Sea-North Sea transition. Mar. Ecol. Prog. Ser. 59, 39-54.

Jørgensen, B. B., and Nelson, D. C. (2004). Sulfide oxidation in marine sediments: geochemistry meets microbiology. Geol. Soc. Am. Spec. 379, 63-81. doi: 10.1130/ 0 -8137-2379-5.63

Jung, J. S., Jang, K. H., Sihn, E. H., Park, S. K., and Park, C. H. (2005). Characteristics of sulfur oxidation by a newly isolated Burkholderia spp. J. Microbiol. Biotechnol. 15, 716-721.

Kjeldsen, K. U., Loy, A., Jakobsen, T. F., Thomse, T. R., Wagner, M., and Ingvorse, K. (2007). Diversity of sulfate-reducing bacteria from an extreme hypersaline sediment, Great Salt Lake (Utah). FEMS Microbiol. Ecol. 60, 287-298. doi: 10.1111/j.1574-6941.2007.00288.x

Kojima, H., Watanabe, T., Iwata, T., and Fukui, M. (2014). Identification of major planktonic sulfur oxidizers in stratified freshwater lake. PLOS ONE 9:e0093877. doi: 10.1371/journal.pone.0093877

Kondo, R., Shigematsu, K., Kawahara, N., Okarmura, T., Yoon, Y. H., Sakami, T., et al. (2012). Abundance of sulphate-reducing bacteria in fish farm sediments along the coast of Japan and South Korea. Fish. Sci. 78, 123-131. doi: 10.1007/ s12562-011-0439-3

Krishnani, K. K., Kathiravan, V., Natarajan, M., Kailasam, M., and Pillai, S. M. (2010). Diversity of sulfur-oxidizing bacteria in Greenwater system of coastal aquaculture. Appl. Biochem. Biotechnol. 162, 1225-1237. doi: 10.1007/s12010009-8886-3

Leloup, J., Fossing, H., Kohls, K., Holmkvist, L., Borowski, C., and Jørgensen, B. B. (2009). Sulfate-reducing bacteria in marine sediment (Aarhus Bay, Denmark): abundance and diversity related to geochemical zonation. Environ. Microbiol. 11, 1278-1291. doi: 10.1111/j.1462-2920.2008.01855.x

Lenk, S., Arnds, J., Zerjatke, K., Musat, N., Amann, R., and Mußmann, M. (2011). Novel groups of Gammaproteobacteria catalyse sulfur oxidation and carbon fixation in a coastal, intertidal sediment. Environ. Microbiol. 13, 758-774. doi: 10.1111/j.1462-2920.2010.02380.x

Liu, J. P., Li, A. C., Xu, K. H., Velozzi, D. M., Yang, Z. S., Milliman, J. D., et al. (2006). Sedimentary features of the Yangtze river-derived along-shelf clinoform deposit in the East China Sea. Cont. Shelf Res. 26, 2141-2156. doi: 10.1016/j.csr. 2006.07.013

Loy, A., Duller, S., Baranyi, C., Mußmann, M., Ott, J., Sharon, I., et al. (2009). Reverse dissimilatory sulfite reductase as phylogenetic marker for a subgroup of sulfur-oxidizing prokaryotes. Environ. Microbiol. 11, 289-299. doi: 10.1111/ j.1462-2920.2008.01760.x

Luo, J. F., Lin, W. T., and Guo, Y. (2011). Functional genes based analysis of sulfuroxidizing bacteria community in sulfide removing bioreactor. Appl. Microbiol. Biotechnol. 90, 769-778. doi: 10.1007/s00253-010-3061-x

Magoè, T., and Salzberg, S. L. (2011). FLASH: fast length adjustment of short reads to improve genome assemblies. Bioinformatics 27, 2957-2963. doi: 10.1093/ bioinformatics/btr507 
Mahmoudi, N., Robeson, M. S., Castro, H. F., Fortney, J. L., Techtmann, S. M., Joyner, D. C., et al. (2015). Microbial community composition and diversity in Caspian Sea sediments. FEMS Microbiol. Ecol. 91, 1-11. doi: 10.1093/femsec/ fiu013

Masuda, S., Bao, Z., Okubo, T., Sasaki, K., Ikeda, S., Shinoda, R., et al. (2016). Sulfur fertilization changes the community structure of rice root-, and soil- associated bacteria. Microbes Environ. 31, 70-75. doi: 10.1264/jsme2.ME15170

Masuda, S., Eda, S., Ikeda, S., Mitsui, H., and Minamisawa, K. (2010). Thiosulfatedependent chemolithoautotrophic growth of Bradyrhizobium japonicum. Appl. Environ. Microbiol. 76, 2402-2409. doi: 10.1128/AEM.02783-09

Meyer, B., Imhoff, J. F., and Kuever, J. (2007). Molecular analysis of the distribution and phylogeny of the $s o x B$ gene among sulfur-oxidizing bacteria-evolution of the Sox sulfur oxidation enzyme system. Environ. Microbiol. 9, 2957-2977. doi: 10.1111/j.1462-2920.2007.01407.x

Meyer, B., and Kuever, J. (2007). Molecular analysis of the diversity of sulfatereducing and sulfur-oxidizing prokaryotes in the environment, using aprA as functional marker gene. Appl. Environ. Microbiol. 73, 7664-7679. doi: 10.1128/ AEM.01272-07

Meyer, D. D., de Andrade, P. A. M., Durrer, A., Andreote, F. D., Corção, G., and Brandelli, A. (2016). Bacterial communities involved in sulfur transformations in wastewater treatment plants. Appl. Microbiol. Biotechnol. 100, 10125-10135. doi: 10.1007/s00253-016-7839-3

Michelsen, C. F., Pedas, P., Glaring, M. A., Schjoerring, J. K., and Stougaard, P. (2014). Bacterial diversity in Greenlandic soils as affected by potato cropping and inorganic versus organic fertilization. Polar Biol. 37, 61-71. doi: 10.1007/ s00300-013-1410-9

Milliman, J. D., and Meade, R. H. (1983). World-wide delivery of river sediment to the oceans. J. Geol. 91, 1-21.

Miyashita, A., Mochimaru, H., Kazama, H., Ohashi, A., Yamaguchi, T., Nunoura, T., et al. (2009). Development of $16 \mathrm{~s}$ rRNA gene-targeted primers for detection of archaeal anaerobic methanotrophs (ANMEs). FEMS Microbiol. Lett. 297, 31-37. doi: 10.1111/j.1574-6968.2009. 01648.x

Müller, A. L., Kjeldsen, K. U., Rattei, T., Pester, M., and Loy, A. (2014). Phylogenetic and environmental diversity of $D s r A B$-type dissimilatory (bi) sulfite reductases. ISME J. 9, 1152-1165. doi: 10.1038/ismej.2014.208

Nie, M., Wang, M., and Li, B. (2009). Effects of salt marsh invasion by Spartina alterniflora on sulfate-reducing bacteria in the Yangtze River estuary, China. Ecol. Eng. 35, 1804-1808. doi: 10.1016/j.ecoleng.2009.08.002

Oksanen, J., Blanchet, F. G., Kindt, R., Legengre, P., Minchin, P. R., O’Hara, R. B., et al. (2011). Vegan: Community Ecology Package. $R$ Package Version 2.0-2. Available at: http://CRAN.R-project.org/package=vegan

Pester, M., Knorr, K. H., Friedrich, M. W., Wagner, M., and Loy, A. (2012). Sulfatereducing microorganisms in wetlands-fameless actors in carbon cycling and climate change. Front. Microbiol. 3:72. doi: 10.3389/fmicb.2012.00072

Petri, R., Podgorsek, L., and Imhoff, J. F. (2001). Phylogeny and distribution of the soxB gene among thiosulfate-oxidizing bacteria. FEMS Microbiol. Lett. 197, 171-178. doi: 10.1016/S0378-1097(01)00111-2

Pham, V. H., Yong, J. J., Park, S. J., Yoon, D. N., Chung, W. H., and Rhee, S. K. (2008). Molecular analysis of the diversity of the sulfide: quinone reductase ( $s q r)$ gene in sediment environments. Microbiology 154, 3112-3121. doi: 10.1099/ mic.0.2008/018580-0

Purcell, A. M., Mikucki, J. A., Achberger, A. M., Alekhina, I. A., Barbante, C., Christner, B. C., et al. (2014). Microbial sulfur transformations in sediments from Subglacial Lake Whillans. Front. Microbiol. 5:594. doi: 10.3389/fmicb. 2014.00594

Quillet, L., Besaury, L., Popova, M., Paissé, S., Deloffre, J., and Ouddane, B. (2012). Abundance, diversity and activity of sulfate-reducing prokaryotes in heavy metal-contaminated sediment from a salt marsh in the Medway Estuary (UK). Mar. Biotechnol. 14, 363-381. doi: 10.1007/s10126-011-9420-5

Reed, H. E., and Martiny, J. B. H. (2013). Microbial composition affects the functioning of estuarine sediments. ISME J. 7, 868-879. doi: 10.1038/ismej. 2012.154

Saarenheimo, J., Tiirola, M. A., and Rissanen, A. J. (2015). Functional gene pyrosequencing reveals core proteobacterial denitrifiers in boreal lakes. Front. Microbiol. 6:674. doi: 10.3389/fmicb.2015.00674

Shen, L., Xu, H., Guo, X., and Meng, L. (2011). Characteristics of large-scale harmful algal blooms (HABs) in the Yangtze River Estuary and the adjacent
East China Sea (ECS) from 2000 to 2010. J. Environ. Prot. 2, 1285-1294. doi: 10.4236/jep.2011.210148

Sievert, S. M., Hügler, M., Taylor, C. D., and Wirsen, C. O. (2008). "Sulfur oxidation at deep-sea hydrothermal vents," in Microbial Sulfur Metabolism, eds C. Dahl and C. G. Friedrich (Berlin: Springer), 238-258. doi: 10.1007/978-3-540-726821_19

Su, C. C., and Huh, C. A. (2002). 210Pb, 137Cs and 239,240Pu in East China Sea sediments: sources, pathways and budgets of sediments and radionuclides. Mar. Geol. 183, 163-178.

Tago, K., Okubo, T., Shimomura, Y., Kikuchi, Y., Hori, T., Nagayama, A., et al. (2014). Environmental factors shaping the community structure of ammoniaoxidizing bacteria and archaea in sugarcane field soil. Microbes Environ. 30, 21-28. doi: 10.1264/jsme2.ME14137

Thomas, F., Giblin, A. E., Cardon, Z. G., and Sievert, S. M. (2014). Rhizosphere heterogeneity shapes abundance and activity of sulfur-oxidizing bacteria in vegetated salt marsh sediments. Front. Microbiol. 5:309. doi: 10.3389/fmicb. 2014.00309

Tourna, M., Maclean, P., Condron, L., O’Callaghan, M., and Wakelin, S. A. (2014). Links between sulphur oxidation and sulphur-oxidising bacteria abundance and diversity in soil microcosms based on soxB functional gene analysis. FEMS Microbiol. Ecol. 88, 538-549. doi: 10.1111/1574-6941. 12323

Treude, T., Krause, S., Maltby, J., Dale, A. W., Coffin, R., and Hamdan, L. J. (2014). Sulfate reduction and methane oxidation activity below the sulfatemethane transition zone in Alaskan Beaufort Sea continental margin sediments: implications for deep sulfur cycling. Geochim. Cosmochim. Acta 144, 217-237. doi: 10.1016/j.gca.2014.08.018

Varon-Lopez, M., Dias, A. C. F., Fasanella, C. C., Durrer, A., and Melo, I. S. (2013). Sulphur-oxidizing and sulphate-reducing communities in Brazilian mangrove sediments. Environ. Microbiol. 16, 845-855. doi: 10.1111/1462-2920.12237

Wang, K., Ye, X. S., Zhang, H. J., Chen, H. P., Zhang, D. M., and Liu, L. (2016). Regional variations in the diversity and predicted metabolic potential of benthic prokaryotes in coastal northern Zhejiang, East China Sea. Sci. Rep. 6:38709. doi: 10.1038/srep38709

Wang, L. P., Zheng, B. H., and Lei, K. (2015). Diversity and distribution of bacterial community in the coastal sediments of Bohai Bay, China. Acta Oceanol. Sin. 34, 122-131. doi: 10.1007/s13131-015-0719-3

Wu, X. J., Pan, J. L., Liu, X. L., Tan, J., Li, D. T., and Yang, H. (2009). Sulfatereducing bacteria in leachate-polluted aquifers along the shore of the East China Sea. Can. J. Microbiol. 55, 818-828. doi: 10.1139/W09-037

Xiong, J. B., Ye, X. S., Wang, K., Chen, H. P., Hu, C. J., Zhu, J. L., et al. (2014). Biogeography of the sediment bacterial community responds to a nitrogen pollution gradient in the East China Sea. Appl. Environ. Microbiol. 80, 1919-1925. doi: 10.1128/AEM.03731-13

Xu, G., Liu, J., Liu, S. F., Wang, Z. B., Hu, G., and Kong, X. H. (2016). Modern muddy deposit along the Zhejiang coast in the East China Sea: response to large-scale human projects. Cont. Shelf Res. 130, 68-78. doi: 10.1016/j.csr.2016. 10.007

Yang, J., Jiang, H. C., Dong, H. L., Wu, G., Hou, W. G., Zhao, W. Y., et al. (2013). Abundance and diversity of sulfur-oxidizing bacteria along a salinity gradient in four Qinghai-Tibetan lakes, China. Geomicrobiol. J. 30, 851-860. doi: 10.1080/01490451.2013.790921

Yang, X., Huang, T. L., Guo, L., Xia, C., Zhang, H. H., and Zhou, S. L. (2015). Abundance and diversity of sulfate-reducing bacteria in the sediment of the Zhou cun drinking water reservoir in Eastern China. Genet. Mol. Res. 14, 5830-5844. doi: 10.4238/2015.May.29.15

Ye, Q., Wu, Y., Zhu, Z. Y., Wang, X. N., Li, Z. Q., and Zhang, J. (2016). Bacterial diversity in the surface sediments of the hypoxic zone near the Changjiang Estuary and in the East China Sea. Microbiologyopen 5, 323-339. doi: 10.1002/ mbo3.330

Yousuf, B., Kumar, R., Mishra, A., and Jha, B. (2014). Unravelling the carbon and sulphur metabolism in coastal soil ecosystems using comparative cultivationindependent genome-level characterisation of microbial communities. PLOS ONE 9:e107025. doi: 10.1317/journal.pone.0107025

Yu, Y., Song, J. M., Li, X. G., Yuan, H. M., and Li, N. (2013). Fractionation, sources and budgets of potential harmful elements in surface sediments of the East China Sea. Mar. Pollut. Bull. 68, 157-167. doi: 10.1016/j.marpolbul.2012. 11.043 
Zhang, W., Song, L. S., Ki, J. S., Lau, C. K., Li, X. D., and Qian, P. Y. (2008). Microbial diversity in polluted harbor sediments II: sulfate-reducing bacterial community assessment using terminal restriction fragment length polymorphism and clone library of $d s r A B$ gene. Estuar. Coast Shelf Sci. 76, 682-691. doi: 10.1016/j.ecss.2007. 07.039

Zhang, Y., Xie, X., Jiao, N., Hsiao, S. S. Y., and Kao, S. J. (2014). Diversity and distribution of amoA-type nitrifying and nirStype denitrifying microbial communities in the Yangtze River estuary. Biogeosciences 10, 17819-17857. doi: 10.5194/bg-11-21312014

Zhang, Y., Zhen, Y., Mi, T. Z., He, H., and Yu, Z. G. (2016). Molecular characterization of sulfate-reducing bacteria community in surface sediments from the adjacent area of Changjiang Estuary. J. Ocean Univ. China 15, 107-116. doi: 10.1007/s11802-016-2781-7
Zhu, D. C., Tanabe, S. H., Yang, C., Zhang, W. M., and Sun, J. Z. (2013). Bacterial community composition of South China Sea sediments through pyrosequencing-based analysis of 16S rRNA genes. PLOS ONE 8:e78501. doi: 10.1371/journal.pone.0078501

Conflict of Interest Statement: The authors declare that the research was conducted in the absence of any commercial or financial relationships that could be construed as a potential conflict of interest.

Copyright (c) 2017 Zhang, Wang, Zhen, Mi, He and Yu. This is an open-access article distributed under the terms of the Creative Commons Attribution License (CC BY).

The use, distribution or reproduction in other forums is permitted, provided the original author(s) or licensor are credited and that the original publication in this journal is cited, in accordance with accepted academic practice. No use, distribution or reproduction is permitted which does not comply with these terms. 